\title{
Transcriptomic analyses of Aedes aegypti cultured cells and ex vivo midguts in response to an excess or deficiency of heme: a quest for transcriptionally- regulated heme transporters
}

\author{
Heather Eggleston ${ }^{1,2}$ and Zach N. Adelman ${ }^{2^{*}}$ (i)
}

\begin{abstract}
Background: Aedes aegypti is the principle vector of many arboviruses, including dengue virus and Zika virus, which are transmitted when an infected female mosquito takes a blood meal in order to initiate vitellogenesis. During blood digestion, $\sim 10 \mathrm{mM}$ heme-iron is ingested into the midgut lumen. While heme acts as both a nutrient and signaling molecule during blood digestion, it can also be highly toxic if left unchaperoned. Both signaling by, and degradation of, heme are intracellular processes, occurring in the nucleus and cytoplasm, respectively. However, the precise mechanism of heme uptake into the midgut epithelium is not currently known.

Results: We used next generation RNA sequencing with the goal to identify genes that code for membrane bound heme import protein(s) responsible for heme uptake into the midgut epithelium. Heme deprivation increased uptake of a heme fluorescent analog in cultured cells, while treatment of midguts with an excess of heme decreased uptake, confirming physiological changes were occurring in these heme-sensitive cells/tissues prior to sequencing. A list of candidate genes was assembled for each of the experimental sample sets, which included Aag2 and A20 cultured cells as well as midgut tissue, based on the results of a differential expression analysis, soft cluster analysis and number of predicted transmembrane domains. Lastly, the functions related to heme transport were examined through RNAi knockdown.
\end{abstract}

Conclusions: Despite a large number of transmembrane domain containing genes differentially expressed in response to heme, very few were highly differentially expressed in any of the datasets examined. RNAi knockdown of a subset of candidates resulted in subtle changes in heme uptake, but minimal overall disruption to blood digestion/egg production. These results could indicate that heme import in Ae. aegypti may be controlled by a redundant system of multiple distinct transport proteins. Alternatively, heme membrane bound transport in $A e$. aegypti could be regulated post-translationally.

Keywords: Heme, Aedes aegypti, Transcriptomes, RNAi, Transporter, Mosquito midgut

\footnotetext{
* Correspondence: zachadel@tamu.edu

${ }^{2}$ Department of Entomology, 329A Heep Center, Texas A\&M University, 370

Olsen Blvd, College Station, TX 77843, USA

Full list of author information is available at the end of the article
}

(c) The Author(s). 2020 Open Access This article is licensed under a Creative Commons Attribution 4.0 International License, which permits use, sharing, adaptation, distribution and reproduction in any medium or format, as long as you give appropriate credit to the original author(s) and the source, provide a link to the Creative Commons licence, and indicate if changes were made. The images or other third party material in this article are included in the article's Creative Commons licence, unless indicated otherwise in a credit line to the material. If material is not included in the article's Creative Commons licence and your intended use is not permitted by statutory regulation or exceeds the permitted use, you will need to obtain permission directly from the copyright holder. To view a copy of this licence, visit http://creativecommons.org/licenses/by/4.0/. The Creative Commons Public Domain Dedication waiver (http://creativecommons.org/publicdomain/zero/1.0/) applies to the data made available in this article, unless otherwise stated in a credit line to the data. 


\section{Background}

The Aedes aegypti mosquito is an insect of substantial medical importance as it vectors viruses such as dengue, chikungunya, yellow fever and Zika, resulting in human morbidity and mortality [1-4]. Viral transmission is dependent on the female ingesting infected vertebrate blood, upon which the virus must pass multiple infection barriers in order to allow for transmission to the next vertebrate host [5]. Once obtained, the bloodmeal taken by Ae. aegypti is digested by enzymes secreted from the midgut epithelium over the course of the 72-h digestion process [6-9]. Two key sources of nutrients obtained from these proteins include amino acids and heme-iron. The amino acids are utilized as building blocks by the mosquito to produce the lipids, carbohydrate and egg proteins necessary for vitellogenesis [10]. While heme acts as both a source of iron that is deposited into the developing eggs [11], it is also a signaling molecule resulting in the activation of vitellogenesis through the activation of the steroid hormone 20-hydroxyecdysone by binding to and stabilizing the nuclear receptor E75 [12-16].

While heme is a vital nutrient, it is also a potent toxin as its pro-oxidant nature leads to the production of reactive oxygen species when left unchaperoned. As a consequence, the female mosquito has developed strategies to limit heme toxicity during blood digestion, beginning with the peritrophic matrix (PM), which is synthesized by the midgut epithelium after blood ingestion and acts as a barrier isolating the epithelial cells from the toxic products of digestion [17]. Comprised of proteins, proteoglycans, and chitin fibrils $[18,19]$, at least one PM protein has been reported to bind heme, Ae. aegypti intestinal mucin 1 (AeIMUCI) $[20,21]$. Heme toxicity is further reduced through its degradation by heme oxygenase in the cytosol of the epithelial cells into biliverdin IX $\alpha$ (BV $\alpha)$, iron and CO [for reviews, see [22, 23]]. Evidence of heme transport into the cytosol and that of its degradation product, biglutaminyl-biliverdin, back out into the lumen was observed by Pereira et al., (2007) who found a color change in the lumen over the course of digestion from heme red to bilin pigment green [24]. Although heme is known to enter the midgut epithelium and its degradation product to exit back into the lumen for excretion, the mechanisms responsible for this transport are unknown.

As the primary membrane-bound heme transporters characterized in vertebrates do not appear to be conserved in Ae. aegypti [25], de novo identification and characterization of novel transporters is needed. We reasoned that similar to prior work identifying novel heme transporters in C. elegans [26], treatment of Ae. aegypti cells with an excess of heme, or with media lacking heme could result in diagnostic transcriptional changes as an attempt to both control heme bioavailability and to limit heme toxicity (heme homeostasis). Bottino-Rojas et al. measured transcriptional changes in an Aedes aegypti cell line in response to heme [27]. Our study builds upon these findings by incorporating multiple cell lines and time points as well as measuring the transcriptional responses of ex vivo dissected midguts exposed to heme. Transcriptomic analysis of these cell lines and midgut tissue resulted in the identification of differentially expressed transcripts, including those containing multipass transmembrane domains associated with potential transport of heme. However, no single gene was found significantly differentially expressed in all conditions, suggesting redundancy in heme hemostasis. A subset of the genes found differentially expressed in both midgut epithelial cells and cultured cells were analyzed through RNAi knockdown; while minor changes in heme uptake were observed, no single gene was found responsible for uptake ability.

\section{Results}

ZnMP visualization of heme import changes in response to heme overload or deficiency

As no heme transport proteins have been identified in any dipteran, we sought to develop an assay to rapidly assess heme transport ability in mosquito cells. In vertebrates, transport of Zinc Mesoporphyrin (ZnMP), a heme fluorescent analog, occurs through the same active transport system as heme [28], indicating that monitoring ZnMP fluorescence could be used to examine changes in mosquito heme transport systems. In mammalian cells, ZnMP could not be degraded by heme oxygenase [29], which allowed for the accumulation of its fluorescent signal over time [28]. In this study, we examined ZnMP fluorescence in Aag2 cells after treatment over a 72-h period with regular growth media (10\% FBS, no added heme), hemedeficient media (no FBS, no added heme) or hemesupplemented media (no FBS, $10 \mu \mathrm{M}$ heme). We observed $\mathrm{ZnMP}$ fluorescence following incubation in $10 \mu \mathrm{M}$ ZnMP regardless of the heme-treatment, indicating Aag2 cells are capable of uptake (Fig. 1a). However, only the hemedeficient treatment had detectable fluorescence when incubated in $5 \mu \mathrm{M} \mathrm{ZnMP}$, indicating an increased ZnMP uptake capacity under heme-deficient conditions. Quantitative analysis of these cells confirmed that heme-starved cells showed increased cellular uptake when compared to either the heme-supplemented cells or those grown in regular media (Fig. 1b). We also note that the heme-supplemented cells showed higher ZnMP uptake than those in regular growth media, suggesting that heme present in the regular growth media exceeds $10 \mu \mathrm{M}$ due to the addition of FBS.

RNA sequencing and differential expression analysis of cultured cell samples exposed to heme-deficiency and heme-overexposure conditions

Having observed changes in heme uptake through ZnMP fluorescence in these conditions, we isolated total 


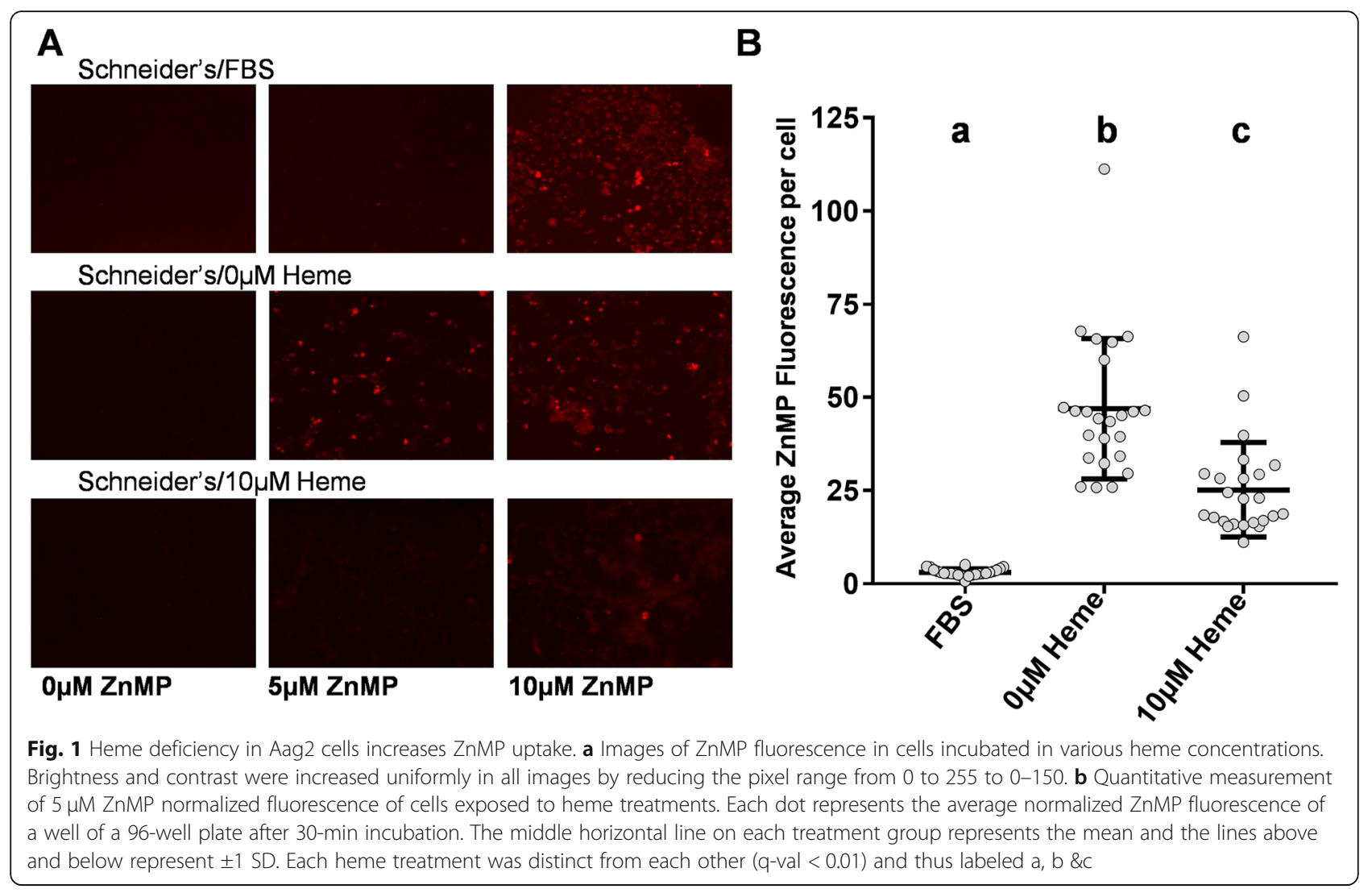

RNA from heme-treated cells, extracted mRNA and performed RNA-seq with the goal to observe heme-induced transcriptomic changes. In order to identify differentially expressed genes across cell types and treatment regimens, three sets of experimental conditions were examined in Aag2 cells and one in A20 cells (Additional file 4, Fig. S1; Table 1). We describe below the results of the transcriptomic analyses performed on Aag2 cells grown in Schneider's Drosophila media.
In heme-exposed Aag2 cells grown in Schneider's Drosophila medium, 8644 annotated transcripts were considered expressed across all samples, with biological replicates clustering together and treatment groups (Regular growth media, $0 \mu \mathrm{M}$ heme \& $10 \mu \mathrm{M}$ heme) distinctly separate (Additional file 4, Fig. S2). Of these, 587 genes were found significantly differentially expressed in the regular growth media vs $0 \mu \mathrm{M}$ heme comparison [Table S1 (Additional file 1); q-value <0.0001; Fig. 2a,

Table 1 Ae. aegypti cultured cell heme exposure experimental conditions and differential expression/cluster analysis results

\begin{tabular}{|c|c|c|c|c|c|c|c|c|c|c|}
\hline \multirow[t]{2}{*}{$\begin{array}{l}\text { Cell } \\
\text { Type }\end{array}$} & \multirow[t]{2}{*}{$\begin{array}{l}\text { Incubation } \\
\text { Time }\end{array}$} & \multicolumn{3}{|c|}{$\begin{array}{l}\text { Type of Growth Media for Experimental } \\
\text { Incubation Time }\end{array}$} & \multicolumn{4}{|c|}{$\begin{array}{l}\text { Differential Expression Comparisons } \\
\text { [genes (genes w/TM domains)] }\end{array}$} & \multicolumn{2}{|c|}{$\begin{array}{l}\text { Cluster Analysis } \\
\text { [genes (genes W/TM } \\
\text { domains)] }\end{array}$} \\
\hline & & Normal & $\begin{array}{l}\text { Heme- } \\
\text { Deficient }\end{array}$ & Heme-Overexposure & $\begin{array}{l}\text { Normal vs } \\
\text { Normal + } 20 \mu \mathrm{M} \\
\text { Heme }\end{array}$ & $\begin{array}{l}\text { Normal vs } \\
0 \mu \mathrm{M} \\
\text { Heme }\end{array}$ & $\begin{array}{l}\text { Normal vs } \\
10 \mu \mathrm{M} \\
\text { heme }\end{array}$ & $\begin{array}{l}0 \mu \mathrm{M} v \mathrm{vs} \\
10 \mu \mathrm{M} \\
\text { heme }\end{array}$ & $\begin{array}{l}\text { Import- } \\
\text { like } \\
\text { clusters }\end{array}$ & $\begin{array}{l}\text { Export- } \\
\text { like } \\
\text { clusters }\end{array}$ \\
\hline Aag2 & $48 \mathrm{~h}$ & $\begin{array}{l}\text { Schneider's } \\
\text { Drosophila+ } \\
\text { FBS }\end{array}$ & N/A & $\begin{array}{l}\text { Schneider's } \\
\text { Drosophila + FBS + } \\
20 \mu \mathrm{M} \text { Heme }\end{array}$ & $551(211)$ & & & & $1611(455)$ & 1391(385) \\
\hline Aag2 & $72 \mathrm{~h}$ & $\begin{array}{l}\text { Schneider's } \\
\text { Drosophila+ } \\
\text { FBS }\end{array}$ & $\begin{array}{l}\text { Schneider's } \\
\text { Drosophila }\end{array}$ & $\begin{array}{l}\text { Schneider's } \\
\text { Drosophila }+10 \mu \mathrm{M} \\
\text { Heme }\end{array}$ & & $587(251)$ & $1990(737)$ & $\begin{array}{l}2274 \\
(856)\end{array}$ & $745(238)$ & $687(240)$ \\
\hline Aag2 & $72 \mathrm{~h}$ & $\begin{array}{l}\text { Leibovitz's L- } \\
15+\text { FBS }\end{array}$ & $\begin{array}{l}\text { Leibovitz's } \\
\text { L-15 }\end{array}$ & $\begin{array}{l}\text { Leibovitz's L- } \\
15+10 \mu \mathrm{M} \text { Heme }\end{array}$ & & $\begin{array}{l}4166 \\
(1218)\end{array}$ & $\begin{array}{l}4979 \\
(1568)\end{array}$ & $\begin{array}{l}3200 \\
(1121)\end{array}$ & $905(229)$ & $670(197)$ \\
\hline A20 & $72 \mathrm{~h}$ & $\begin{array}{l}\text { Leibovitz's L- } \\
15+\text { FBS }\end{array}$ & SF900 II & $\begin{array}{l}\text { SF900 } \|+10 \mu \mathrm{M} \\
\text { Heme }\end{array}$ & & $745(300)$ & $2815(658)$ & $\begin{array}{l}3692 \\
(942)\end{array}$ & $1109(448)$ & 757(143) \\
\hline
\end{tabular}


d]. For the other comparisons, 1990 genes were found differentially expressed in the normal media vs $10 \mu \mathrm{M}$ heme comparison (Fig. 2b, e) and 2274 when comparing the $0 \mu \mathrm{M}$ heme and $10 \mu \mathrm{M}$ heme groups (Fig. 2c, f). As we were most interested in membrane-bound transporters, transmembrane (TM) domain predictions were performed on all DE genes; 251, 737 and 856 were identified respectively with at least $1 \mathrm{TM}$ domain. Interestingly, for all comparisons the number of differentially expressed genes with predicted TM domains was significantly more than expected by chance alone (obs 251, exp. 185; obs 737, exp. 638; obs 856, exp. 729; all $p$ values $<0.00001)$. Despite the large number of DE genes, we note that the magnitude of transcriptional change of TM-containing genes was overall quite small. When genes that contained 2 or more TM domains and a greater than 2-fold change between heme treatment types were examined, only 2 were downregulated in response to heme deficiency and upregulated in response to heme exposure: AAEL009206 and AAEL009813. AAEL009206 is described as an organic cation transporter, while AAEL009813 is annotated as glutamate receptor 7 .
Similar analyses were performed on the other sets of experimental conditions (48-h heme-treated Aag2 cells, 72-h heme-treated A20 cells and 72-h heme-treated Aag2 cells in L-15; described in Table 1) and are discussed in more detail in the supplemental text (Additional file 3). All of the varying heme treatments in each set of experimental conditions showed similar expression between biological replicates and dissimilar between the treatments types (Additional file 4, Fig. S3A, S4 \& S5). The number of DEGs and the amount that contain at least 1 transmembrane domain are given in Table 1 (48h heme-treated Aag2: Additional file 4, Fig. S3B\&C, Table S2; A20: Fig. S6A-F, Table S3; heme-treated Aag2 in L-15: Fig. S7A-F, Table S4; All supplement tables: Additional file 1). In addition, a small number of highly expressed (2-fold up/down) multi-transmembrane domain containing genes with expression patterns consistent with that expected for genes associated with heme transport were found in each dataset; 28 genes in 48-h heme treated Aag2 cells, 98 in 72-h heme treated A20 cells and 13 in 72-h heme treated Aag2 cells in L-15 media. Surprisingly, when we compared the lists of DEG to each other we found no overlap, and so decided to

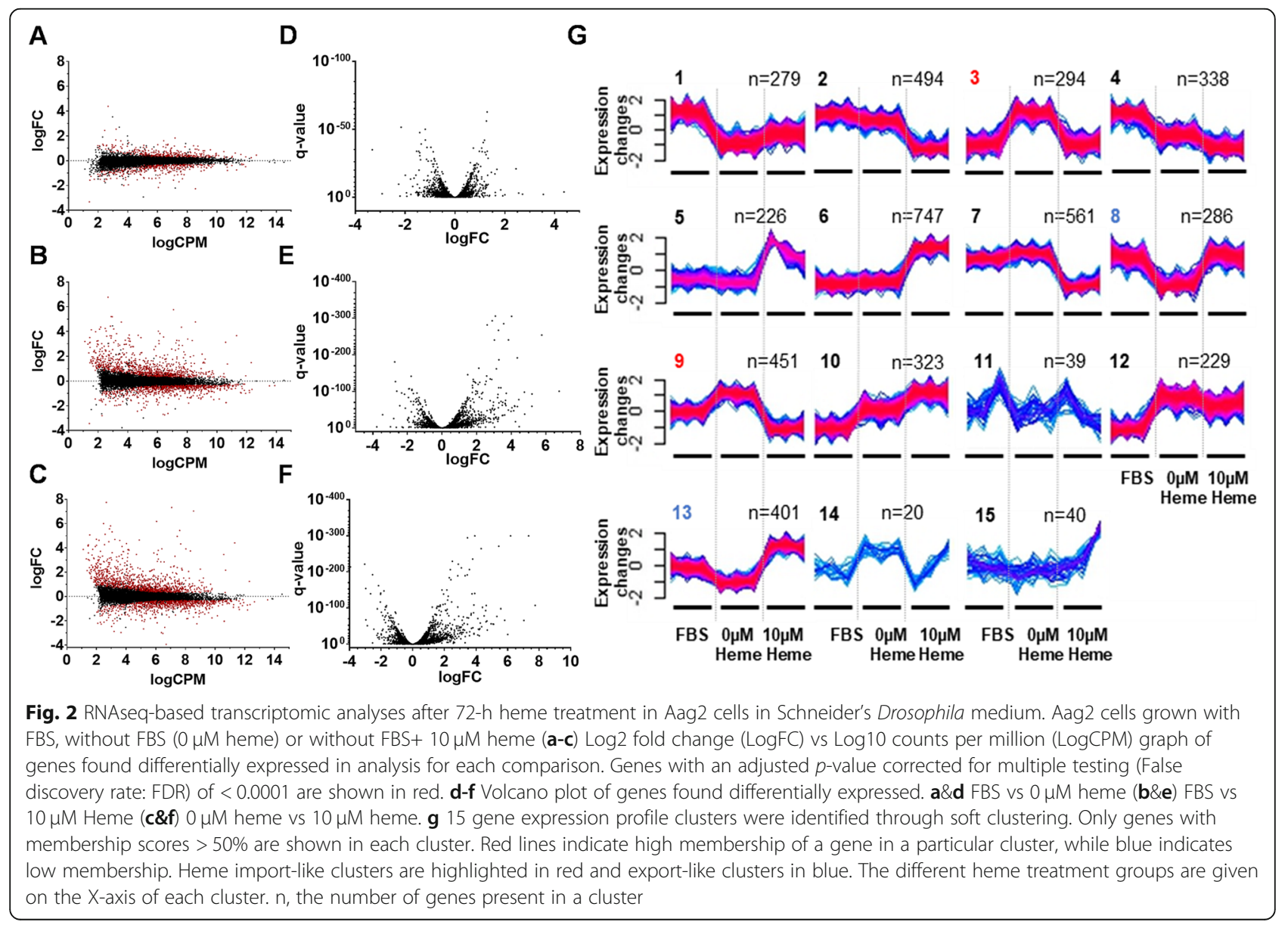


pursue an alternative method of transcriptomic analysis based on cluster analysis.

\section{Soft cluster analysis of cultured cells exposed to heme- deficiency and heme-overexposure conditions}

As an alternative to strict differential expression analysis, we examined expression patterns across each treatment to identify those genes with a pattern of expression consistent with our expectations for transcriptionallyregulated heme transport proteins (Import/Export: upregulated/downregulated upon heme deficiency, downregulated/upregulated upon heme excess). When we examined the transcriptome of 72-h heme-treated Aag2 cells grown in Schneider's Drosophila media, 4728 genes were assigned across 15 distinct cluster patterns (Each gene displayed $>50 \%$ membership confidence to its assigned cluster), as shown in Fig. 2g (Table S1). Genes that showed the expected expression pattern for those with heme import function ( $\uparrow$ heme-deficiency, $\downarrow$ hemeoverexposure) are shown in clusters 3 and 9; these clusters contained 238 genes with 1 or more predicted TM domain (85 and 153, respectively). Clusters 8 and 13 contained genes with the expression pattern consistent with potential heme export function $(\downarrow$ heme-deficiency, $\uparrow$ heme-overexposure) and included 240 genes (99 and 142 respectively) with at least $1 \mathrm{TM}$ domain prediction. Our analysis also appeared to identify clusters associated with gene expression changes due to the alterations in nutrient content in the growth media when fetal bovine serum is present/absent (clusters 1, 4, 10 and 12). Similar clusterbased analyses were performed for other experimental conditions (Table 1) are described in detail in the supplemental text (Additional file 3). For each, the number of genes assigned to the import-like clusters and export-like clusters and the number that contain at least 1 predicted transmembrane domain are given in Table 1 (48-h hemetreated Aag2: Fig. S3D; 72-h heme-treated A20: Fig. S6G; 72-h heme-treated Aag2 in L-15: Fig. S7G).

When the differential expression and the soft cluster analyses were compared to each other for each set of cultured cell conditions (Table 1), many of the heme transporter candidate genes identified in one were also found in the other (Additional file 4, Fig. S8-11). In addition, when the genes found highly differentially regulated ( $>2$-fold/down; $\geq 2 \mathrm{TM}$ ) in each dataset were compared to those identified in the import-like/export-like clusters, the majority were present in both (48-h hemetreated Aag2: 28/28; 72-h heme-treated A20: 84/98; 72-h heme-treated Aag2 in L-15: 12/13). This commonality between the two different analyses indicated that these approaches converged on a single set of differentially regulated genes. In the end, as the majority of the highly expressed multipass TM containing DEGs were also present in import-like or export-like clusters for each dataset, we considered that these genes might play a role in the cellular response to heme. For example, both of the genes found highly differentially expressed (AAEL009206 \& AAEL009813) were also present in the export-like clusters.

We reasoned that genes undergoing similar expression changes upon heme treatment/deficiency across different media types (L-15 or Schneider's) or cell types (Aag2 or A20) would be the strongest candidates for a role in heme homeostasis. We identified those genes shared between experiments (Table 1) based on their expression pattern (cluster analysis) and number of predicted TM domains ( $\geq 1$ TM domains) (Additional file 4, Fig. S12) and found that the majority of genes in expression clusters consistent with heme export $(n=649)$ or import ( $n=767)$ function were unique to only 1 of the 4 datasets (Table 2). However, considering import-like gene expression patterns, 223 genes were identified in $2 / 4$ datasets, 46 genes were identified in 3/4 datasets and just two (AAEL006432 and AAEL014003) were identified by cluster analysis in all 4 cell culture experiments. Likewise, a small number of genes displayed heme exportlike expression patterns in multiple datasets, with 136 genes found in $2 / 4$ datasets and 11 in $3 / 4$ datasets. No genes with the expression pattern expected for a heme export function were found in all 4 datasets.

\section{Comparing candidate genes to those identified in previously published analyses}

As we observed substantial variability in the suite of differentially regulated genes between cell line type and even growth media conditions in response to heme, we sought to compare our candidate lists with other published experiments. DEGs and the genes present in the import-like/export-like clusters were compared to previous analyses performed in Aag2 cells [27] and bloodfed Ae. aegypti females [30] to identify genes shared between them. Bottino-Rojas [27] found 28 DEG ( $\geq 2$-fold/down, $\geq 2 \mathrm{TM}$ ) in Aag2 cells exposed to heme for $24 \mathrm{~h}$ that contained predicted functions related to transport. Of these genes, 22 were also identified as a DEG and/or present in an import-like/export-like cluster in at least one of our cultured cell experiments ( 7 genes in all 4 datasets, 3 genes in 3 datasets, 8 genes in 2 datasets \& 4 genes in just 1 dataset). The functions of some of these 22 shared genes include $3 \mathrm{ABC}$ transporters, 1 member of the ZIP family of zinc transporters (AAEL014762) and 1 cystinosin (AAEL006113) and 7 of unknown function. AAEL014762 is an iron transporter localized in the endocytic vesicles and is important in exporting iron from the midgut [31, 32]. Cystinosin is involved in the transport of cystine into the cytosol which then serves as a site for redox reactions to occur, indicating its important role in heme-generated ROS mitigation. Thus, the remaining genes present across 
Table 2 Genes Present in Import-like or Export-like Clusters Across Multiple Ae. aegypti Cultured Cell Datasets

\begin{tabular}{lcccc}
\hline & \multicolumn{3}{l}{ Genes Present in One or More Datasets } & \\
\cline { 2 - 5 } & only 1 dataset & 2 datasets & 3 datasets & 4 datasets \\
\hline Genes present in clusters consistent with heme export & 649 & 136 & 11 & 0 \\
Genes present in clusters consistent with heme import & 767 & 223 & 46 & 2 \\
\hline
\end{tabular}

multiple analyses may represent promising candidates as heme transporters. Likewise, of the $\sim 369$ multipass TM containing genes found highly differentially expressed in bloodfed vs sugar fed females $(>1 \log 2$ or $<-1 \log 2 ; \geq 100$ reads in at least 1 sample) [30], almost half $(171,46 \%)$ were also identified as a DEG and/or present in an import-like/export-like expression cluster in one or more of our cultured cell experiments. In fact, the gene AAEL009853 (trysin/serine protease) was differentially expressed in both A20 cells in the absence of the FBS $(0 \mu \mathrm{M}$ heme samples) and bloodfed females and is involved in the digestion of proteins. In addition, the cytinosin AAEL006113 was also upregulated in both bloodfed midguts and heme-exposed cells (A20 \&Aag2) indicating the possibility of a shared ROS response pathways between them. Altogether, these analyses highlight both the plasticity of the Ae. aegypti transcriptional response to heme deficiency/excess and a number of candidate genes that might serve as heme transporters. As no single candidate gene appeared dominant across all experiments, we sought further evidence of transcriptional response to heme directly in the mosquito midgut prior to beginning reverse genetic analyses of candidate genes,

\section{ZnMP uptake in Aedes aegypti midguts}

As Ae. aegypti midgut epithelial cells are directly involved in heme uptake and digestion following blood feeding [33], we decided to examine their transcriptional responses upon heme exposure. As a typical blood meal taken in by the female mosquito is composed of many different components present in vertebrate blood, we attempted to disentangle their effects on the midgut by using a protein-free artificial bloodmeal [with either 0 $\mathrm{mM}$ or $10 \mathrm{mM}$ heme; protocol from [34]]. We initially chose $10 \mathrm{mM}$ heme concentration as that would be the maximum amount of heme present in a drop of blood that could be released at once [18], however smaller concentrations as low as $625 \mu \mathrm{M}$ were also examined. Nevertheless, this method was not effective due to the failure to solubilize heme in aqueous feeding solutions and the corresponding toxicity of solvent such as DMSO. Therefore, an ex vivo application was performed with midguts incubated post-dissection in either regular growth cultured cell media, heme-deficient media $(0 \mu \mathrm{M}$ heme) or heme-overload media (10 $\mu \mathrm{M}$ heme) followed by a ZnMP fluorescence assay based on the adapted insect cultured cell assay [28]. Following ZnMP incubation, the heme-treated midguts showed substantially decreased uptake of the fluorescent analog compared to those incubated in regular or heme-deficient media (q-value< 0.0001; Fig. 3a, S13). However, unlike our observations in cultured cells, no significant difference was observed in ZnMP fluorescence between the normal growth media and heme-starved midguts (qvalue $=0.3903$ ). The decreased ZnMP uptake we observed in the $10 \mu \mathrm{M}$ heme treatment indicated that this concentration was sufficient to alter the physiological readiness of the midguts in a manner similar to what might occur naturally during blood digestion. We considered the possibility that this reduction in ZnMP fluorescence was due to a more general decrease in active transport, rather than a specific downregulation of heme transport. To test this possibility, heme-exposed midguts were incubated with $\mathrm{pHrodo}^{\mathrm{mt}}$ green dextran as a marker for active endocytosis (Fig. 3b). No difference in fluorescence was observed between the heme deficient/overexposure midguts, suggesting that endocytosis is active upon heme-exposure and that the heme transport pathway(s) is specifically affected.

\section{RNA sequencing and differential expression analysis of Heme-treated Midguts}

As the ability of the midgut to uptake the heme analog ZnMP was reduced after incubation with heme, we hypothesized that this was due to modulation of the gut transcriptome, as the cells temporarily downregulated genes involved in heme import and/or upregulated genes involved in heme export similar to what was observed in C. elegans [26]. To test this hypothesis, we performed a differential expression analysis. Few differentially expressed genes were identified when using the strict qvalue (false discovery rate) as in the cultured cell datasets $(65$ DEG, q-value $=0.0001)$. However, as substantially more variation was observed between the biological replicates in this experiment (Additional file 4, Fig. S14) we considered less stringent q-values as well (Table 3; Additional file 1, Table S5). We found as many as 243 (q-value $=0.05$ ) significant DE genes with 125 downregulated and 118 upregulated genes in response to heme exposure (Fig. 3c\&d). Of these, 44\% (108) contained at least one predicted TM domain, with 60 downregulated and 48 upregulated (Additional file 1, Table S5). As observed previously in cultured cells, genes encoding at least one TM domain were much more likely 


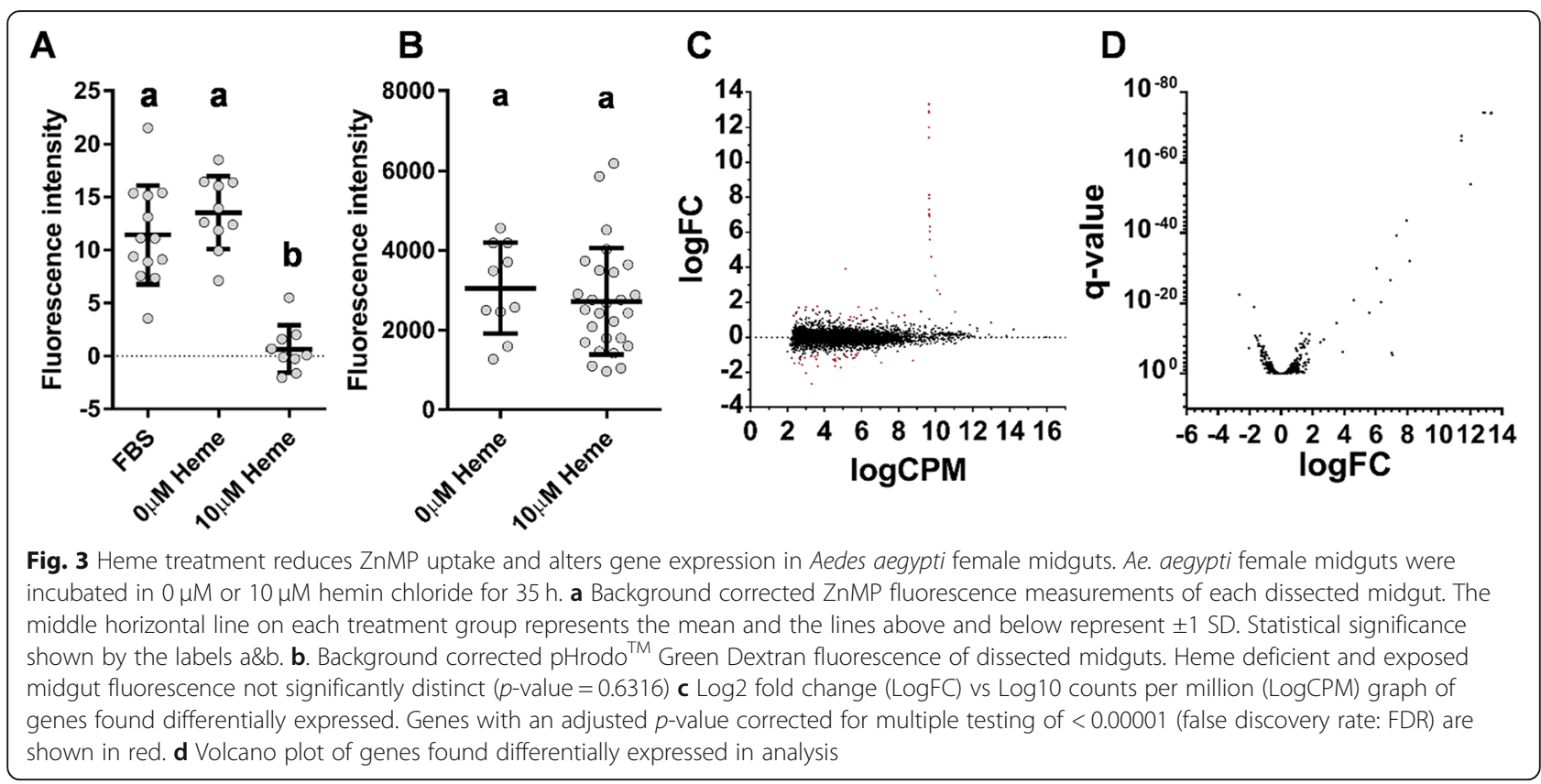

to be differentially regulated in response to heme exposure than expected by chance alone (obs 108, exp. 80; $p$ value $<0.00001$ ). Unexpectedly, we identified that 11 of the most highly upregulated genes were mitochondrial in origin (logFC range 2.7-12) and were highly expressed across all the samples $(\log C P M \sim 10)$. These mitochondrial genes were not considered further, as we sought to focus on genes encoding factors that might shuttle diet-derived heme through the cellular membranes. This left 58 DEGs with 2 or more TM domains, 34 of which were downregulated and 24 upregulated in the presence of heme. This list was further reduced by removing from consideration those gene products with functions not related to transport, such as those with enzymatic activity or those related to the ROS stress response (Genes remaining: 40; 28 downregulated and 12 upregulated; Table 4). Of the 40 DEG candidates, only 11 were highly differentially regulated when exposed to heme overload conditions, 2-fold decrease (6) or increase (5).

In order to confirm that the differentially expressed genes identified in this analysis were in fact transcriptionally regulated in heme exposed Ae. aegypti midguts, we performed quantitative real-time PCR (RT-qPCR) on

Table 3 The number of significant genes found at different $a$ values

\begin{tabular}{lll}
\hline Adjusted $\boldsymbol{a}$ & \# of genes & \# of TM genes \\
\hline 0.0001 & 65 & 38 \\
0.001 & 84 & 47 \\
0.01 & 154 & 76 \\
0.05 & 243 & 108 \\
\hline
\end{tabular}

a small subset of these genes. The computationally derived fold change values of 5 TM-containing genes with increased/ decreased expressionin the presence of heme were compared to the relative quantification (RQ) RT-qPCR values (Fig. 4). In 4 out of the 5 genes examined AAEL002406, AAEL002557, AAEL009531 and AAEL012440 the RT-qPCR results were consistent, all of which showed downregulation in response to heme exposure. Of the 5 genes examined, 2 contained q-values above the $\alpha$ considered in the differential expression analysis (0.05), while one of these, AAEL002406 (0.070), showed consistant downregulation in response to heme exposure, the RT-qPCR results of the other, AAEL000434 (0.064), were not consistant with the upregulation observed previously. These results indicate that the true false discovery rate of this experiment is above the $\alpha$ chosen for this analysis.

\section{Comparison of Midgut Heme transporter candidates to those found in cultured cells}

We compared the list of genes differentially expressed in the midgut upon heme treatment to those genes identified as differentially expressed in the cultured cell analyses with the goal to identify any common heme response mechanisms shared between the distinct cell types examined. In total, 15 of the 40 DEG identified in the midgut were also present in one or more cultured cell datasets. When examining those 28 genes downregulated in the presence of heme (expression pattern consistent with heme import function), 11 were also identified in at least one cell culture experiment [ 8 were identified in only 1 cell dataset, 1 in 2 datasets and 2 in 3 datasets (Table 5)]. Likewise, 4 of the 12 midgut genes 
Table 4 Multipass TM domain containing genes with expression patterns consistent with genes encoding heme transport proteins

\begin{tabular}{|c|c|c|c|}
\hline NAME & $\log 2 \mathrm{FC}$ & q-value & \# TM \\
\hline AAEL000859 protein_coding & -1.3184 & 1.40E-08 & 2 \\
\hline AAEL019869 protein_coding & -1.2359 & 1.05E-05 & 2 \\
\hline AAEL002557 cationic amino acid transporter & -1.1718 & $9.42 \mathrm{E}-07$ & 12 \\
\hline AAEL024460 protein_coding & -1.1243 & 0.00115 & 4 \\
\hline AAEL020936 protein_coding & -1.0454 & $6.14 \mathrm{E}-05$ & 2 \\
\hline AAEL021618 protein_coding & -1.032 & 0.02785 & 2 \\
\hline AAEL024267 protein_coding & -0.982 & 0.00343 & 2 \\
\hline AAEL003619 sodium/chloride dependent amino acid transporter & -0.9543 & 0.00042 & 12 \\
\hline AAEL001938 ATP-binding cassette sub-family A member 3 & -0.8521 & 0.00624 & 17 \\
\hline AAEL007191 amino acid transporter & -0.8341 & 0.00233 & 10 \\
\hline AAEL010905 protein_coding & -0.826 & 0.00082 & 6 \\
\hline AAEL005013 protein_coding & -0.789 & 0.00148 & 2 \\
\hline AAEL012440 sodium-bile acid cotransporter & -0.7835 & 4.60E-05 & 10 \\
\hline AAEL001495 protein_coding & -0.7597 & 0.01199 & 6 \\
\hline AAEL004513 neurotransmitter gated ion channel & -0.7512 & 0.00589 & 3 \\
\hline AAEL008664 protein_coding & -0.7068 & 0.00188 & 2 \\
\hline AAEL006480 protein_coding & -0.7036 & 0.00573 & 3 \\
\hline AAEL014355 symbol, putative & -0.6857 & 0.04023 & 2 \\
\hline AAEL003618 sodium/chloride dependent amino acid transporter & -0.6854 & 0.04341 & 12 \\
\hline AAEL009531 niemann-pick C1 & -0.6551 & 0.00052 & 14 \\
\hline AAEL012226 protein_coding & -0.6385 & 0.02752 & 4 \\
\hline AAEL009112 protein_coding & -0.6322 & 0.03157 & 2 \\
\hline AAEL011918 protein_coding & -0.6194 & 0.02778 & 2 \\
\hline AAEL027190 protein_coding & -0.5945 & 0.00269 & 8 \\
\hline AAEL000461 protein_coding & -0.5927 & 0.00551 & 3 \\
\hline AAEL000417 monocarboxylate transporter & -0.5895 & 0.02177 & 12 \\
\hline AAEL003318 oligopeptide transporter & -0.5479 & 0.01182 & 10 \\
\hline AAEL021771 protein_coding & -0.5258 & 0.03568 & 3 \\
\hline AAEL006855 UDP-galactose transporter & 0.469 & 0.04311 & 10 \\
\hline AAEL012395 ATP-binding cassette transporter & 0.5554 & 0.02778 & 12 \\
\hline AAEL023104 protein_coding & 0.6348 & 0.02177 & 4 \\
\hline AAEL027424 protein_coding & 0.7912 & 0.00758 & 8 \\
\hline AAEL018150 protein_coding & 0.8105 & 0.03276 & 13 \\
\hline AAEL022465 protein_coding & 0.8262 & 0.02191 & 3 \\
\hline AAEL028119 protein_coding & 0.8301 & 0.01236 & 2 \\
\hline AAEL002129 protein_coding & 1.0183 & 3.69E-05 & 2 \\
\hline AAEL005043 ATP-dependent bile acid permease & 1.1916 & $8.42 \mathrm{E}-05$ & 17 \\
\hline AAEL002599 protein_coding & 1.2418 & 3.07E-05 & 2 \\
\hline AAEL021284 protein_coding & 1.6055 & 1.95E-06 & 2 \\
\hline AAEL029008 protein_coding & 1.7825 & $5.04 \mathrm{E}-12$ & 2 \\
\hline
\end{tabular}




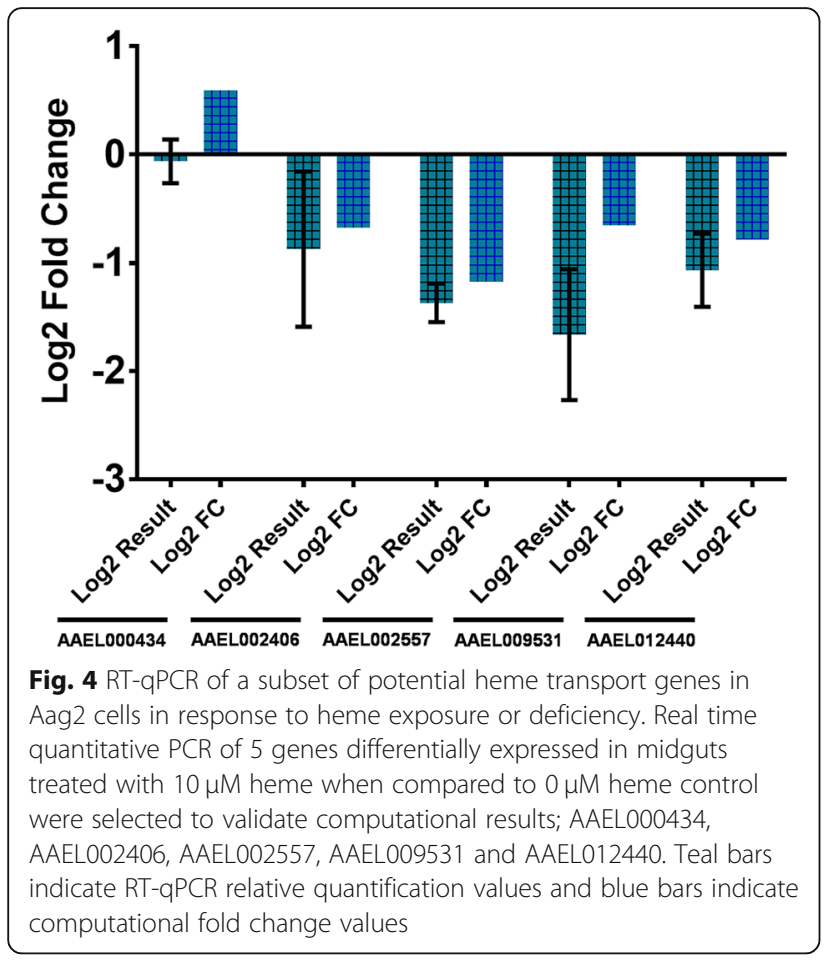

upregulated in the presence of heme (expression consistent with heme export function) were also identified in one cultured cell dataset (Table 5).

\section{RNAi of Aedes aegypti cultured cells}

We next sought to determine whether any of differentially regulated genes has a functional role in heme transport (Table 6). We selected 9 candidate DEG found in both the heme-exposed midgut epithelial cells and at least one cultured cell experiment and performed an RNAi knockdown screen in Aag2 cells, measuring the normalized ZnMP fluorescence in the presence/absence of each gene product (Fig. 5a). RT-qPCR of each gene confirmed successful knockdown for 7/9 candidate genes (Fig. 5d). Knockdown of the gene AAEL001495 ( $p$ value $=0.0004)$ resulted in a reduction of $\mathrm{ZnMP}$ fluorescence (19.9\%) indicating a potential role in heme import (Fig. 5b). Conversely, knockdown of the genes AAEL012226 $(p$-value $=0.0363)$, AAEL008664 $(p$-value $=$ 0.0104), AAEL000417 $\quad(p$-value $=0.0036) \quad$ and AAEL000461 $(p$-value $=0.0356)$ resulted in a modest increase in ZnMP fluorescence when compared to EGFP (23.8, 28.4, 13.8 and $13.8 \%$ respectively) indicating their possible role in heme export. As knockdown of AAEL003619 and AAEL012226 were not confirmed, their potential role in heme transport remains unresolved.

As we observed significant changes in ZnMP fluorescence for 5 candidate genes when knocked down in Aag2 cells, we designed new dsRNAs targeting independent regions of the top 3 genes in order to confirm their role in heme transport. In this RNAi screen the genes AAEL001495 (decreased fluorescence previously), AAEL008664 (increased) and AAEL012226 (increased) as well as AAEL012440 which showed a non-significant downward trend higher in magnitude than some significant genes $(15.8 \%$ decrease; $p$-value $=0.2813)$ were knocked down (Fig. 5b). RT-qPCR of each gene confirmed successful knockdown in all but AAEL012440 (Fig. 5e). The results of this analysis, shown in Fig. 5c, confirmed only AAEL008664 as having a potential role in heme transport, specifically heme export, as a modest increase in ZnMP fluorescence $(24.4 \% ; p$-value = 0.00059 ) was observed in both screens.

\section{RNAi of Aedes aegypti Midguts}

As no clear single candidate gene emerged from our cell culture-based RNAi screen, we repeated the screen using ex vivo dissected midguts under the assumption that redundancy in heme transport might be reduced in this tissue as compared with undifferentiated cells. To do this, we injected dsRNA targeting one of eight DEG with expression patterns consistent with involvement in heme transport, dissected the midguts and measured ZnMP uptake (Table 7, Fig. 6a\&b). Of the 8 genes selected, 5 were found differentially expressed in both midgut

Table 5 Midgut heme transporter candidates found also in one or more cultured cell dataset

\begin{tabular}{|c|c|c|c|c|c|c|c|}
\hline \multicolumn{4}{|c|}{ Potential importers } & \multicolumn{4}{|c|}{ Potential exporters } \\
\hline Midgut + 1 & +2 & +3 & +4 & Midgut + 1 & +2 & +3 & +4 \\
\hline AAEL012226 & AAEL011918 & AAEL012440 & & AAEL027424 & & & \\
\hline AAEL021771 & & AAEL001495 & & AAEL028119 & & & \\
\hline AAEL019869 & & & & AAEL006855 & & & \\
\hline AAEL005013 & & & & AAEL012395 & & & \\
\hline \multicolumn{8}{|l|}{ AAEL006480 } \\
\hline \multicolumn{8}{|l|}{ AAEL003619 } \\
\hline \multicolumn{8}{|l|}{ AAEL000461 } \\
\hline AAEL000417 & & & & & & & \\
\hline
\end{tabular}


Table 6 Cultured cell candidates selected for RNAi knockdown in Aag2 cells

\begin{tabular}{lllll}
\hline Gene & Annotation & \# TM & Dataset Identified in & Type of transport \\
\hline AAEL000417 & monocarboxylate transporter & 12 & A20 & Import \\
AAEL000461 & protein_coding & 3 & A20 & Import \\
AAEL001495 & protein_coding & 6 & Aag2 48 h/A20/Aag2Schn & Import \\
AAEL002557 & cationic amino acid transporter & 12 & Aag2 48 $\mathrm{h}$ & Export \\
AAEL003619 & Na/Cl dependent amino acid transporter & 12 & Aag2 L15 & Import \\
AAEL004513 & neurotransmitter gated ion channel & 3 & Aag2 48h & Export \\
AAEL008664 & protein_coding & 2 & Aag2 48 h/Aag2Schn & Export \\
AAEL012226 & protein_coding & 4 & Aag2 48h/Aag2Schn & Import/Export \\
AAEL012440 & sodium-bile acid cotransporter & 10 & Aag2 48h/A20/Aag2L15 & Import \\
\hline
\end{tabular}

epithelial cells and at least one cultured cell experiment, while 3 were DE unique to the midgut epithelial cells. The RNAi-based knockdown of 4 genes resulted in a decreased in ZnMP fluorescence ( $p$-value $\leq 0.001$ ) with the highest reduction occurring during the knockdown of AAEL00417 (34.9\%), indicating a potential role in heme import. Correspondingly, 2 genes showed an increase in ZnMP fluorescence upon knockdown ( $p$-value $\leq 0.0049)$ with the highest increase occurring in AAEL002557 $(25.2 \%)$ and thus may play a role in heme export.
While knockdown of 4 of the 8 genes tested resulted in a significant decrease in ZnMP uptake, each one contributed less than a $35 \%$ reduction in ZnMP fluorescence. To test whether these genes contribute to heme import into the midgut epithelium through independent redundant systems, a mixture of dsRNAs targeting AAEL000417, AAEL003318, AAEL004513 and AAEL012440 was injected into female mosquitoes alongside an EGFP control dsRNA. However, when the level of RNAi-based knockdown was evaluated using RT-qPCR, significant reduction of

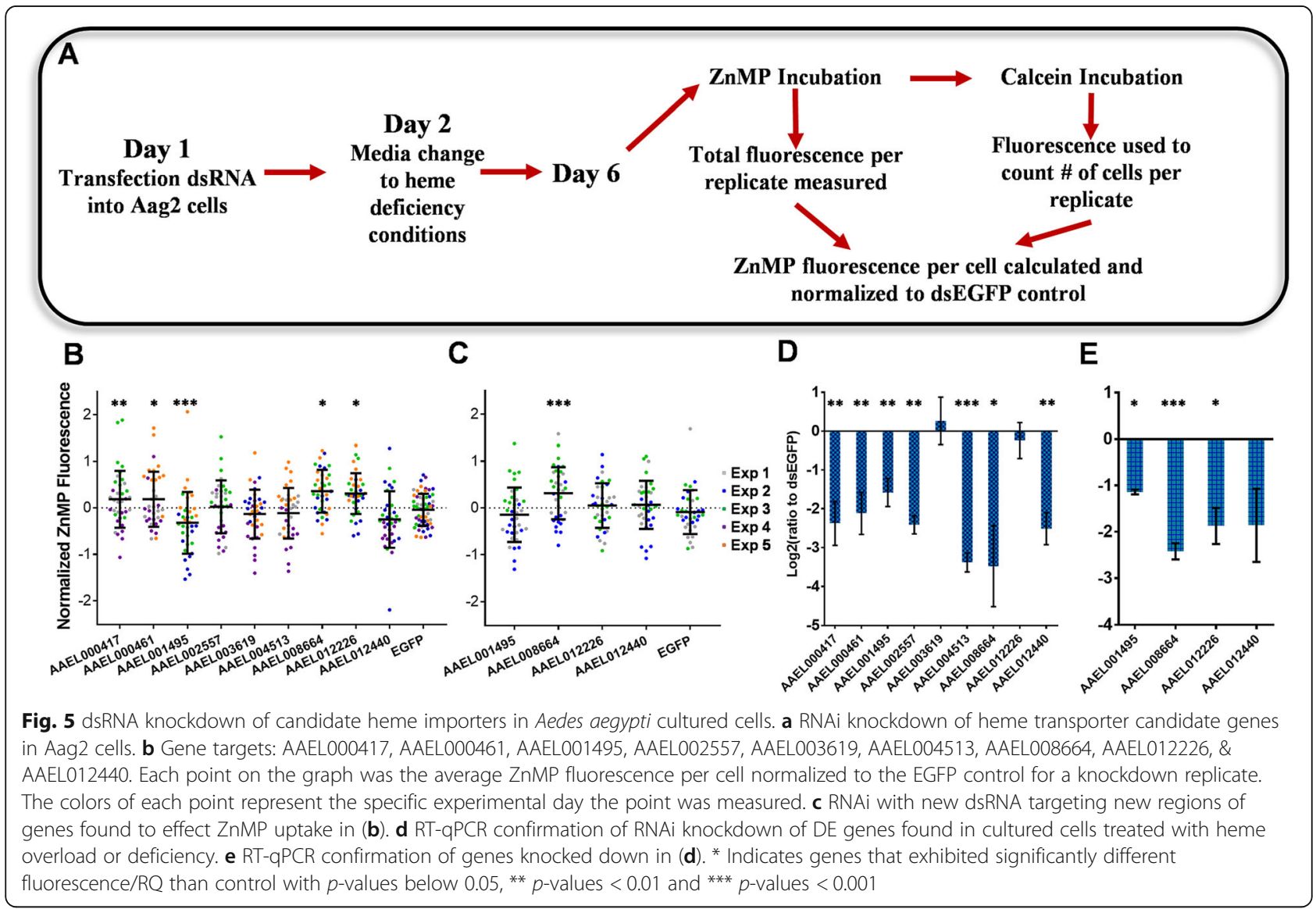


Table 7 Midgut heme transporter candidates selected for RNAi knockdown in adult Ae. aegypti

\begin{tabular}{|c|c|c|c|c|}
\hline Gene ID & $\log 2 \mathrm{FC}$ & FDR & Annotation & \# TM \\
\hline AAEL000417 & -0.58947 & 0.02177 & monocarboxylate transporter & 12 \\
\hline AAEL000461 & -0.59269 & 0.00551 & protein_coding & 3 \\
\hline AAEL001938 & -0.85206 & 0.00624 & ATP-binding cassette sub-family A member 3 , putative & 17 \\
\hline AAEL002557 & -1.17180 & $9.42 \mathrm{E}-07$ & cationic amino acid transporter & 12 \\
\hline AAEL003318 & -0.54787 & 0.01182 & oligopeptide transporter & 10 \\
\hline AAEL004513 & -0.75116 & 0.00589 & neurotransmitter gated ion channel & 3 \\
\hline AAEL009531 & -0.65507 & 0.00053 & niemann-pick C1 & 14 \\
\hline AAEL012440 & -0.78354 & $4.60 \mathrm{E}-05$ & sodium-bile acid cotransporter & 10 \\
\hline
\end{tabular}

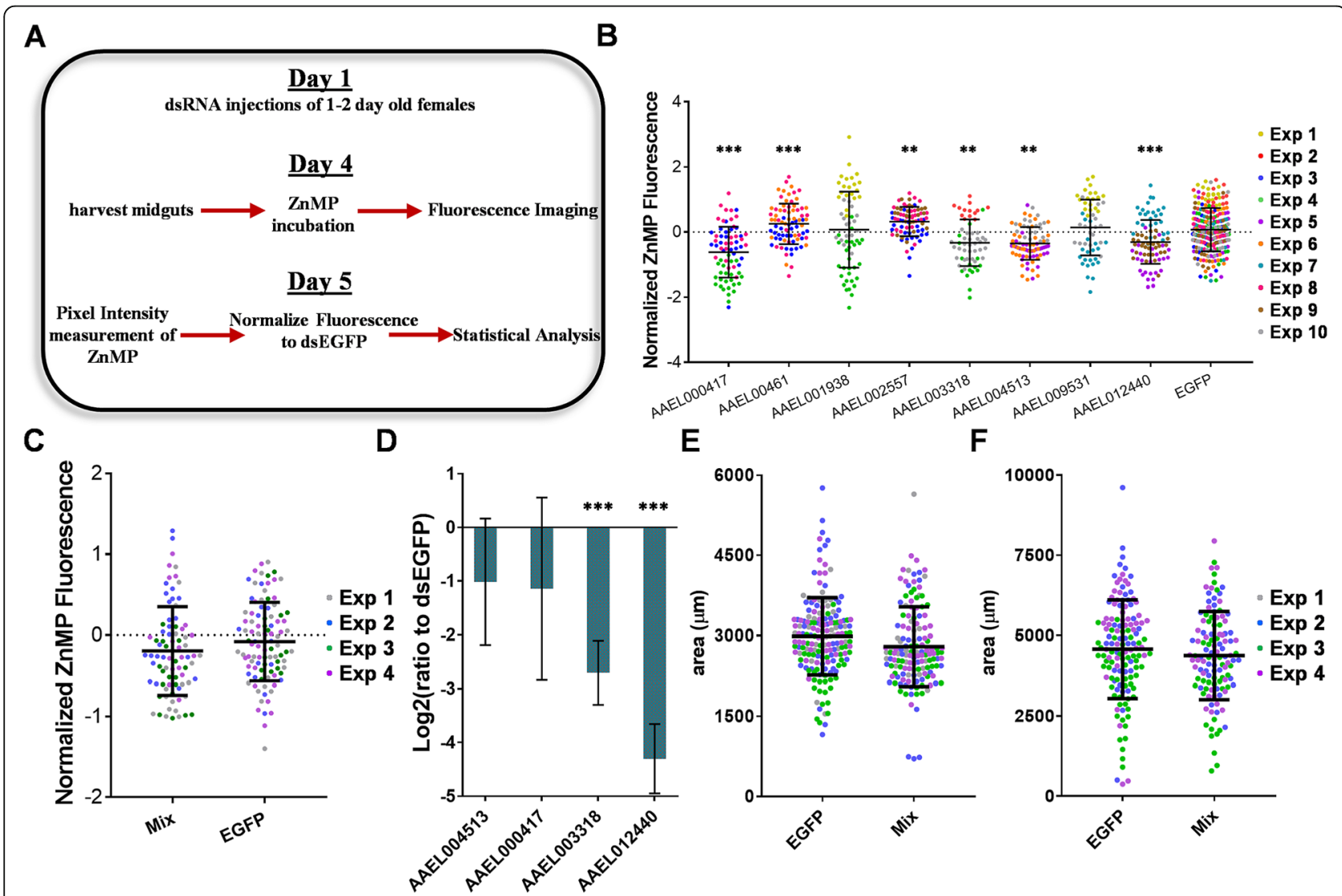

Fig. 6 dsRNA knockdown in adult Aedes aegypti female midguts of candidate genes. a RNAi knockdown of the Ae. aegypti genes AAEL000417, AAEL000461, AAEL001938, AAEL002557, AAEL003318, AAEL004513, AAEL009531 and AAEL012440 in Ae. aegypti female midguts. b ZnMP fluorescence observed after RNAi knockdown of candidate heme transporter genes. Each colored point represents the average ZnMP fluorescence across a midgut normalized to an EGFP control. The colors of each point represent the specific experimental day that the point was observed; each experiment consisted of a sample size of $\sim n=30$ for each gene. ${ }^{* *}$ Indicates genes that exhibited significantly different fluorescence than control with $p$-values below 0.01 and ${ }^{* * *}$ with $p$-values $<0.001$. c ZnMP fluorescence of simultaneous RNAi knockdown of 4 genes, AAEL000417, AAEL003318, AAEL004513 and AAEL012440 in adult female mosquitoes. d AAEL003318 \& AAEL012440 showed RT-qPCR confirmation of RNAi knockdown as they were distinct from the expression in cells targeted with dsEGFP (*** $=p$-val $<0.001)$. (e\&f) Reproductive potential was measured through area measurements of ovaries at (e) $12 \mathrm{~h}$ and (f) $24 \mathrm{~h}$ post blood feeding. A slight decrease was observed at 12 $h$ in the mix group ( $p$-val $=0.0191)$ while no difference was observed at $24 \mathrm{~h}(\mathrm{p}-\mathrm{val}=0.2723)$ 
transcripts was observed for only 2 of the 4 genes (AAEL003318 \& AAEL012440) (Fig. 6d). Following dissection of the midguts 4 days later and $\mathrm{ZnMP}$ treatment, the ZnMP uptake was compared between the EGFP control and the AAEL003318/AAEL012440 dsRNA group. Surprisingly, no difference in ZnMP uptake was observed between the candidate dsRNA group and the control ( $p$-value $=$ 0.3451 ) (Fig. 6c). As heme is an essential signal in vitellogenesis, we reasoned that decreased heme uptake might result in delayed ovarian growth following a bloodmeal. Ovaries were dissected from mosquitoes injected with the dsRNA mixture at $12 \mathrm{~h}$ (Fig. 6e) and $24 \mathrm{~h}$ (Fig. 6f) post blood feed. Consistent with our expectation, ovary size was significantly smaller in the experimental group at $12 \mathrm{~h}$ after blood feeding $(p$-value $=0.0191)$. However, this difference was not observed at the 24 -h time point ( $p$-value $=0.2723$ ), indicating that any delay in vitellogenesis was only temporary.

\section{Discussion}

Despite the importance of heme as a functional group in many proteins, its use as a signaling molecule, and its role as a nutrient in Ae. aegypti, intracellular heme trafficking is not well understood in this mosquito species. Dietary heme from a bloodmeal, but not synthesized heme, also serves as a signal for vitellogenesis [12-16]. Therefore, we conducted transcriptomic analyses of $A e$. aegypti midguts and cell lines to identify genes whose expression was altered upon heme overexposure or deficiency conditions with the goal to identify genes that encode transporters of heme across cellular membranes, like those found in C. elegans and R. microplus [26, 35]. Our differential expression and soft cluster analyses indicated that mosquito cell lines alter the expression of many genes in response to heme deficiency. Surprisingly, only a small number of multipass transmembrane domain containing DEG were both highly differentially expressed (2-fold/down) and displayed one of the hypothesized expression patterns for genes with heme import ( $\uparrow$ in heme deficiency \& $\downarrow$ in heme exposure) or export functions ( $\downarrow$ in heme deficiency \& $\uparrow$ in heme exposure) in each dataset. However, when these candidate lists were cross-compared between DEG experiments, there was little to no overlap. This failure to identity one or more strongly differentially expressed multipass transmembrane protein across the cell lines and conditions examined suggests the possibility that each cell line could have a redundant system of heme import, whereby multiple transport proteins each contribute to the total heme accumulation in the cell. Alternatively, it is possible that these cells lines regulate heme transport translationally or post-translationally, and thus differences would not be measurable in these analyses.
Transcriptomic changes in response to heme-exposure in Aag2 cells [27] and blood feeding in adult females [30] have been explored previously. When the multipass transmembrane domain containing genes present in these analyses were compared to the DEGs and the genes present in the import-like/export-like clusters identified in our cultured cell analyses, a small number of genes were found in common between them. BottinoRojas et al. (2015) exposed Aag2 cells to $50 \mu \mathrm{M}$ heme for $24 \mathrm{~h}$, resulting in $28 \mathrm{DEG}(\geq 2 \mathrm{TM})$ with predicted functions related to transport and fold changes greater than 2 -fold. However, they tested a higher heme concentration for a shorter incubation time than what was explored in this set of experiments. As the majority of the 28 DEG were also found in at least one of our cultured cell heme-exposure experiments (78.6\%), similar differential expression patterns can be inferred despite both the differing experimental heme incubation times and concentrations performed. Additionally, our analyses led to the identification of another 249 genes (2-fold/down, $\geq 2 \mathrm{TM}$ ) with predicted functions related to transport across all our experimental conditions not previously identified by Bottino-Rojas et al. Bonizzoni et al. (2011) explored the transcriptomic changes induced by a bloodmeal in adult females $5 \mathrm{~h}$ post feeding and found $<400$ highly expressed DEG with 2+ TM domains. Of these, $46 \%$ of these were found either differentially expressed or present in import-like or export-like clusters in our cultured cell analyses. In addition, only $3.9 \%$ of all TM containing DEG present in bloodfed females were also differentially expressed in heme-exposed midguts. This disimilarity between the datasets could be due to differences in cell/tissue (Whole female carcass vs cultured cells/midgut tissue) examined or particular hemetreatment performed (whole vertebrate blood vs heme alone). As Bonizzoni et al. (2011) performed their transcriptomic analysis with the whole female mosquito, they emphasized those DE genes found across the carcass, not those specific to the midgut epithelium.

Our transcriptomic analysis of heme-exposed midguts resulted in 243 DEG, of which 40 were identified as candidates for genes with potential heme transport function based on the prediction of $2+$ transmembrane domains and predicted functions either related to transport or were unknown. Out of the 243 DEGs we noted that 11 highly upregulated genes in response to hemeexposure were of mitochondrial origin. Whether this is due to specific modulation of these genes or general proliferation of the mitochondria in response to heme is unclear, however changes in mitochondrial biogenesis could be verified through measurement of the ratio of mitochondrial and nuclear-encoded proteins $[36,37]$. Overall we observed low differential expression in our ex vivo midgut transcriptomic analysis 
which could be due to the high variability observed between all of the heme replicate samples (Fig. S14). This extra source of variability in the dataset could have reduced the statistical power of the DE analysis, overall lowering the height of the expression changes observed. This variability could potentially be reduced if heme-exposure was examined at an earlier timepoint to limit the time spent in the cultured medium prior to measurement.

As we were most interested in identifying membrane bound heme transporters either exclusively present in midgut epithelial cells, or present in multiple tissues/life stages including the adult female midgut, we performed RNAi knockdown of a subset of the 40 genes in both cultured cells and midgut epithelial cells. Across the two cultured cell knockdown experiments, only AAEL008664 showed significantly increased ZnMP uptake compared to the EGFP control. However, the increase in fluorescence observed, $28.8 \%$, was modest, suggesting that more than one gene product might be responsible for heme transport into and out of the cell. When an RNAi knockdown screen was performed on adult female midguts, 4 genes were identified with putative functions in heme import which showed a modest reduction in ZnMP uptake of $>20 \%$. Additionally, the fact that only modest ZnMP fluorescence changes were observed post knockdown could be due to membrane-bound proteins having a lower average protein turnover rate than soluble ones $[38,39]$. To test the hypothesis that multiple genes may be involved in heme transport, 2 genes were successfully knocked down simultaneously (AAEL003318 and AAEL012440), however the decreased fluorescence observed previously was not reproduced. Both genes were also observed as highly upregulated in the previous differential expression analysis of 5-h post blood feeding adult females vs sugar fed (AAEL003318: $\sim 18$-fold increase; AAEL012440: 2.08-fold increase), implying a role in blood digestion [30]. In addition, a sodium bile acid cotransporter (IrSigP-109,984), orthologous to AAEL012440 (through reciprocal best match), was implicated in blood digestion in Ixodes ricinus ticks, which could indicate a convergent regulatory mechanism across blood-feeders [40].

Direct orthologues of characterized vertebrate heme transport proteins [41-44] were not found in Ae. aegypti [25]. This informed our decision to perform de novo identification and characterization of novel transporters through examination of transcriptomic changes observed due to heme deficiency and overexposure conditions. However, after the start of this project, a novel heme transport protein, $\mathrm{ABCB} 10$, was characterized in the tick $R$. microplus $[35,45]$. Like $C$. elegans, $R$. microplus lacks a functional heme biosynthesis pathway [35, 46]. An orthologue to ABCB10, AAEL000434, is present in Ae. aegypti, however it was not differentially expressed in any of the analyses performed in this study.

It is possible that regulation of heme transport occurs, not transcriptionally as was tested in the analyses described in this study, but rather translationally or posttranslationally. This hypothesis could be tested through a proteomic analysis at various time points post heme exposure, though such an analysis would be limited to the detection of overall changes in protein abundance and thus could not distinguish all potential protein regulatory changes. A proteomic analysis was recently performed in this mosquito targeting the peritrophic matrix and its heme binding proteins [34], the protocol of which could be adapted here to examine midgut epithelial cells instead. Otherwise, gain of function studies could be performed in a model organism such as yeast [47] or C. elegans that has been modified to temporarily remove native heme import functionality [48]. Yeast preferentially uptake iron to synthesize their own heme rather than scavenging exogenous heme [49]; however, a separate heme uptake system is activated when heme biosynthesis is compromised. As a result, strains deficient in the FET3 protein (Ferroxidase component of Fe transport complex) could serve as a recipient for potential heme/iron transporters from Ae. aegypti. Despite the potential of this system to characterize heme transport proteins, the rescue of heme import in a model organism would be dependent on proper exogenous protein folding as well as the transport protein's ability to function as a homo-oligomer. Lastly, while this study has provided evidence against one or a few highly differentially regulated genes involved in heme transport in the Ae. aegypti mosquito, much work remains to pin down what type of regulation is responsible for changes in heme uptake and which genes are directly responsible for heme transport during blood digestion.

\section{Conclusions}

In this study, we examined the response of two Ae. aegypti cultured cell lines and midgut epithelial tissue to heme overload or deficiency conditions in order to identify novel genes involved in heme transport as no genes with heme transport capacity have been identified in this mosquito previously. Both of the cultured cell types appear to upregulate heme import in heme deficiency conditions, while in heme-exposed midguts, a downregulation of heme import in response to heme overload was observed. Transcriptomic analyses did confirm differential expression in response to heme deficiency and heme overload in cultured cells. However, despite observing many DEG between the heme treatments in each analysis, no strong candidates for genes critical for heme transport were found. This could indicate that either the cells examined have a redundant system of heme import 
with the total heme accumulation in each cell due to multiple transport proteins or that these cells do not regulate heme transport transcriptionally. In the end, only one potential membrane bound heme transport gene, AAEL008664 was identified through the RNAi screen in Aag2 cultured cells, a protein of unknown function, although further work is necessary to identify its cellular location, and specific function. In the adult RNAi screen, four genes were initially identified with potential roles in heme import due to modest decreases in ZnMP fluorescence. However, upon simultaneous knockdown of two of these genes, AAEL003318 and AAEL012440, the resulting fluorescence failed to indicate a corresponding change in the heme import pathway suggesting more work is needed to elucidate the specific functions of these genes. In conclusion, the knowledge provided by this study yields valuable insight into the regulatory responses initiated during heme deficiency and overload conditions and the membrane bound heme transport system in Ae. aegypti.

\section{Methods}

Cultured cell growth conditions

Ae. aegypti A20 and Aag2 cells were maintained in Leibovitz's L-15 media (Gibco) supplemented with 10\% FBS (Atlanta Biologicals) and 1\% Pen-strep (Corning) at $28^{\circ} \mathrm{C}$. Aag2 cells were also maintained in Schneider's Drosophila Media (Thermo Fisher) with 10\% FBS (Atlanta Biologicals) and $1 \%$ Pen-strep (Corning) at $28^{\circ} \mathrm{C}$. Both cell lines are available upon request.

\section{Mosquito rearing}

For all experiments, Aedes aegypti (Liverpool strain; obtained from Virgina Tech) was reared at $28^{\circ} \mathrm{C}$ in humidified growth chambers at $70 \% \mathrm{RH}$ and a day: night cycle of $14 \mathrm{H}: 10 \mathrm{H}$. The mosquito colony was maintained on defibrinated sheep blood (Colorado Serum Company, $\mathrm{CO})$. Females 1-3 days old were selected for all experiments. All mosquitoes were fed a $10 \%$ sucrose solution with $1 \%$ Penicillin-streptomycin 2 days prior to dissection and a $10 \%$ sucrose solution prior to dsRNA injection. All females were starved of $10 \%$ sucrose $12 \mathrm{~h}$ prior to blood feeding.

\section{Qualitative assay of ZnMP uptake in mosquito cultured cells}

Zinc Mesoporphyrin (ZnMP) (Frontier Scientific, Logan, UT) stock solution $(0.3 \mathrm{mM})$ was made following a previously described protocol [50]. Following filter sterilization (pore diameter $0.22 \mu \mathrm{m}$ ); the solution was aliquoted and stored at $-20{ }^{\circ} \mathrm{C}$ until needed. Cultured cells (Aag2 in Schneider's Drosophila media) seeded onto 6-well plates were incubated for $72 \mathrm{~h}$ in normal growth media, media + $0 \mu \mathrm{M}$ heme (heme-deficient) or media $+10 \mu \mathrm{M}$ heme (heme-overexposure). All subsequent steps were performed in a cell culture hood in the presence of minimal light $\left[0.4 \mathrm{~lm} / \mathrm{ft}^{2}\right.$ on average as measured with a $\mathrm{HOBO}$ data logger (Part \#U12-012; Onset; Bourne, MA)] to prevent degradation of the ZnMP. ZnMP uptake was performed $(0,5 \& 10 \mu \mathrm{M})$ for $30 \mathrm{~min}$ in uptake buffer following a procedure adapted from Worthington et al., 2001. The uptake buffer used during the incubation and wash procedures consisted of $50 \mathrm{mM}$ HEPES, pH 7.4, 130 $\mathrm{mM} \mathrm{NaCl}, 10 \mathrm{mM} \mathrm{KCl}, 1 \mathrm{mM} \mathrm{CaCl} 2$ and $1 \mathrm{mM} \mathrm{MgSO}_{4}$. Following the incubation, the cells were washed once with uptake buffer $+5 \%$ BSA, then $2 x$ with uptake buffer. Cells were imaged in $1 x$ PBS at 100x magnification using the DsRED filter or the propidium iodide (PI) filter of the EVOS FLoid Cell Imaging Station (Thermo Fisher) or the Zeiss Axio Observer Microscope (Carl Zeiss Microscopy, Thornwood NY).

\section{Quantitative ZnMP assay in mosquito cultured cells}

Aag2 cells incubated for $48 \mathrm{~h}$ in normal growth media, heme deficient media and heme overexposure media, were harvested and reseeded onto a 96-well black clear bottomed BRANDplate ${ }^{\oplus}$ Cell grade Premium (Brand Wertheim, Germany) at $2 \times 10^{6}$ cells $/ \mathrm{mL}$ per well and 32 wells per treatment type. Twenty-four hours later, the 96 well plate was incubated with $5 \mu \mathrm{M}$ ZnMP $(100 \mu \mathrm{L} /$ well) for $30 \mathrm{~min}$ at $28^{\circ} \mathrm{C}$. The same wash steps were performed as previously described. Next, $2.5 \mu \mathrm{M}$ Calcein AM (Thermo Fisher) diluted in $1 \times$ PBS was added to each well and incubated at $28{ }^{\circ} \mathrm{C}$ for $30 \mathrm{~min}$. The average of 21 fluorescence measurements taken across each well at Ex. 540/Em. 580 using a Spectramax i3x (Monochromator, Fluorescent \& Well Scan options selected) was obtained. The number of cells present in each well was determined by Calcein fluorescence using a MiniMax 300 (MiniMax, Imaging \& Endpoint options selected) (Molecular Devices, San Jose CA) using the green channel (Ex. 456/Em. 541). A total of 4 photos (5 ms exposure \& $120 \mu \mathrm{m}$ focus adjustment) were taken per well centering around the middle of each well. The number of cells per well was counted by using the discrete object analysis in the SoftMax ${ }^{\odot}$ Pro Software MiniMax Imaging Edition v6.5.1 to identify cells based on the size and shape of their green fluorescence. The 'draw on image' option was selected to allow customized selection of cells during the counting procedure. The ZnMP fluorescence per cell was calculated by dividing the mean fluorescence per well by the number of cells counted for each well. As the data failed the D'AgostinoPearson omnibus normality test, the mean ZnMP fluorescence/cell for each treatment was compared using the Kruskal-Wallis and Dunn's multiple comparisons tests as performed by GraphPad Prism v7.02 (San Diego, CA). 


\section{Quantitative ZnMP and $\mathrm{pHrodo}^{\mathrm{TM}}$ green dextran assays of ex vivo Ae. aegypti midguts}

In the initial ex vivo experiment, midguts from 3 to 5 day old sugar fed female $A$. aegypti $(n=60)$ were dissected in $1 \mathrm{x}$ PBS, transferred to a biosafety cabinet and split evenly between 3 treatments in 6-well culture plates ( $2 \mathrm{~mL}$ media/well). Midguts were subject to one of the following treatments: Schneider's Drosophila Media (Thermo Fisher) with 10\% FBS (Atlanta Biologicals) and 1\% Pen-strep (Corning) (FBS), Schneider's Drosophila Media $+1 \%$ Pen-strep $(0 \mu \mathrm{M}$ Heme $)$ and Schneider's Drosophila Media $+1 \%$ Pen-strep $+10 \mu \mathrm{M}$ Hemin Chloride (Sigma-Aldrich) (10 $\mu$ M Heme).

All midgut samples were incubated at $28^{\circ} \mathrm{C}$ for $35 \mathrm{~h}$ with midguts transferred into fresh media on a new plate every $8-12 \mathrm{~h}$. Following the media incubation, the midguts were incubated with $10 \mu \mathrm{M}$ ZnMP for $30 \mathrm{~min}$ at $28^{\circ} \mathrm{C}$ or with $100 \mu \mathrm{g} / \mathrm{mL}$ pHrodo $^{\mathrm{mm}}$ green dextran (Thermo Fisher Scientific, Waltham MA) for $20 \mathrm{~min}$ at $37^{\circ} \mathrm{C}$. Photos were taken using the DsRED (ZnMP) or GFP filter (Dextran) of the Leica M165 FC stereomicroscope equipped with a DFC3000C digital camera at 16x magnification. Photos of $0 \mu \mathrm{M}$ ZnMP/Dextrantreated midguts were taken prior to fluorophore incubation from a subset of the midguts in each treatment group. The resulting images were analyzed by ImageJ [51] to determine mean pixel intensity per midgut background corrected to remove channel and tissue auto fluorescence. Means were either compared using a one-way ANOVA with individual means compared using Tukey's multiple comparisons test or an unpaired two-tailed t-test as performed by GraphPad Prism v7.02 (San Diego, CA). If the data failed the D'Agostino-Pearson omnibus normality test, Kruskal-Wallis test and Dunn's multiple comparisons test were performed instead.

\section{Heme treatments and sample preparation for RNA-seq of both cultured cells and midgut tissue}

Aag2 and A20 cultured cells were exposed to heme deficiency and overexposure conditions across 4 different experiments as described in Table 1 . All 4 experiments had 3 biological replicates performed per heme treatment. Heme exposed midgut samples were also prepared from dissected midguts (3-5-day sugar fed females) incubated in the $0 \mu \mathrm{M}$ Heme and $10 \mu \mathrm{M}$ heme treatments previously described. A total of 4 biological replicates were performed with 30 pooled midguts per replicate which were snap frozen in liquid nitrogen at the end of the incubation period. For all samples, RNA was isolated using the TRIzol reagent (Thermo Fisher), following the manufacturer's protocol. The resulting RNA was DNase treated (DNase I: New England Biolabs) and then quantified using a Nanodrop (Thermo
Fisher). One microgram of total RNA of each sample was prepared for sequencing using the TruSeq RNA v2 Illumina library preparation kit (Illumina San Diego, CA) or the NEBNext Ultra RNA library preparation kit (New England Biolabs Ipswich, MA). Both protocols utilized sequential first and second strand cDNA synthesis with random priming and PCR library enrichment of 10 cycles.

\section{Sequencing \& Computational Analysis of Heme-exposed cultured cells and Midguts}

Paired-end mRNA sequencing with $150 \mathrm{bp}$ read length was performed on all cultured cell samples on an Illumina HiSeq 2500 (Genomics Sequencing Center at the Virginia Biocomplexity Institute). Single-end sequencing with $75 \mathrm{bp}$ read length was performed on all hemeexposed midgut samples on an Illumina Nextseq 500 (Texas A\&M's Institute for Genome Sciences and Society). Reads were aligned to the Ae. aegypti reference genome [AaegL5, obtained from www.vectorbase.org [38]] using HISAT2 v2.1.0 with default parameters [52] through Texas A\&M's High Performance Research Computing Ada server. Mapped reads were sorted and reads with low quality mapping scores were removed $(-\mathrm{q} 10)$ with SAMtools view and SAMtools sort v1.7. The number of reads per mRNA transcript was calculated with the BEDtools suite v2.19.1. Differential expression was determined using the exact test [53] as implemented in EdgeR [54] at a false discovery rate (FDR) of 0.0001. FDR was calculated using the 'topTags' function with the default $p$-value correction method 'BH' [55]. Transmembrane domain predictions of the DEGs were determined by the TOPCONS webserver [56]. The number of TM domain containing genes in a random subset of genes from the Ae. aegypti genome ( $n=\#$ of DEG in the comparison tested) was determined using custom scripts (additional file 5). The mean number and standard deviation of 30 random samples was calculated for each of the differential expression analyses. Finally, a two-tailed z-test was performed for each comparison tested to determine whether the number of TM containing genes found in the analyses were significantly distinct from those found by chance alone.

Soft cluster analysis was performed on all cultured cell datasets using the Mfuzz $\mathrm{R}$ package $[57,58]$. Default parameters were followed except for the following: the optimal fuzzifier value, $\mathrm{m}$, was determined using the mestimate function and the optimal number of clusters were determined using the cselection function. All four datasets were also compared by using 4-way Venn diagrams, comparing the import-like clusters and the export-like clusters between the datasets [59]. 


\section{Reverse genetic experiments in Aedes aegypti cultured cells and adult females dsRNA production}

PCR amplicons of each candidate heme importer were generated using Phusion polymerase (New England Biolabs Ipswich, MA), primers listed in Supplemental Table 6 and cDNA generated from female Ae. aegypti Liverpool strain mosquitoes as template. The EGFP amplicon was based off a GFP containing plasmid, Ac5-STABLE1-neo a gift from Rosa Barrio \& James Sutherland (Addgene plasmid \#32425; http://n2t.net/addgene:32425; RRID:Addgene_32,425) [60]. An additional set of primers targeting different regions of the genes AAEL001495, AAEL004657, AAEL008664, AAEL012226, AAEL012440 were designed as well. The MEGASCRIPT RNAi kit (Thermo Fisher) was used to make the dsRNA with T7 polymerase enzyme making both strands during the same 5 -h incubation at $37^{\circ} \mathrm{C}$. The resulting dsRNA was nuclease treated to remove any ssRNA and dsDNA template remaining in the sample followed by purification using the MEGACLEAR kit (Thermo Fisher).

\section{Transfection of cultured cells}

dsRNA transfections were performed using Effectene (Qiagen Hilden, Germany) following the standard transfection protocol with cells at 70-80\% confluency. Specifically, $2.5 \mu \mathrm{g}$ of dsRNA, $8 \mu \mathrm{L}$ Enhancer, $129.5 \mu \mathrm{L}$ Buffer EC and $25 \mu \mathrm{L}$ Effectene was used for each well of a 6-well plate. A control dsRNA targeting GFP was performed with each plate. At $24 \mathrm{~h}$ post transfection, the media was replaced in each well with $2 \mathrm{~mL}$ Schneider's Drosophila media $+1 \%$ Pen-strep (Heme-deficient). At 3 days post transfection, the cells were harvested and reseeded at $2 \times$ $10^{6}$ cells $/ \mathrm{mL}$ per well with a total volume in each well of $100 \mu \mathrm{L}$ into a 96-well black clear bottomed BRANDplate ${ }^{\circ}$ Cell grade Premium (Brand Wertheim, Germany) 12 wells per dsRNA, with any remaining cells pelleted by centrifugation at $4{ }^{\circ} \mathrm{C}$ and frozen at $-80^{\circ} \mathrm{C}$ after discarding the supernatant. Transfected cells seeded in 96 well plates were incubated with $5 \mu \mathrm{M} \mathrm{ZnMP}$ for $30 \mathrm{~min}$ at $28^{\circ} \mathrm{C}$, $100 \mu \mathrm{L}$ solution per well, $24 \mathrm{~h}$ later. The $\mathrm{ZnMP}$ and Calcein incubation, wash procedures and fluorescent imaging were performed as described above.

\section{Statistical analysis in cultured cells}

The ZnMP fluorescence per cell values were then normalized to the exogenous GFP control dsRNA values. The lme4 package in the $\mathrm{R}$ statistical software was used to run a linear mixed-effects model analysis [61]. GFP was set as the reference for the analysis using the relevel command. The hypothesized formula for the model is given below with the relationship between cell fluorescence and dsRNA gene knockdown accounting for the potential random effects due to the day each experiment was performed.

$$
\text { Fluorescence } \sim \text { Gene }+(1 \mid \text { Day })+\varepsilon
$$

Finally, all data for each replicate was pooled and graphed using GraphPad Prism v7.02 (San Diego, CA).

\section{Injection}

A total of $400 \mathrm{ng}$ dsRNA was injected into each adult female Ae. aegypti using a Nanoject III microinjector (Drummond) with a glass needle drawn from a capillary. For each dsRNA, 3 replicates were performed with $\sim 30$ females per replicate. A pooled dsRNA group was also performed (400 ng/dsRNA) with the genes AAEL000417, AAEL003318, AAEL004513 and AAEL012440 except each replicate was $\sim 90$ females. Pooling occurred directly following quantification of newly prepared dsRNA, adding $400 \mathrm{ng}$ of each dsRNA per mosquito to be injected to a microcentrifuge tube, followed by freezing aliquots at $-80^{\circ} \mathrm{C}$ until the day of injection. A control group of females was injected for each experiment with dsRNA targeting EGFP.

\section{Dissection, ZnMP incubation and fluorescence measurement in adults}

At 3 days post injection, $\sim 30$ midguts were dissected from the surviving females in $1 \mathrm{x}$ PBS and placed into $1.5 \mathrm{~mL}$ microcentrifuge tubes. A 30-min incubation in $10 \mu \mathrm{M}$ $\mathrm{ZnMP}$ at room temperature was performed in aluminum foil covered microcentrifuge tubes placed on a tube rotator (VWR). Once the ZnMP incubation and wash steps were finished, treated midguts were placed on microscope slides in 1xPBS sectioned off with an ImmEdge ${ }^{\text {nx }}$ hydrophobic barrier pen (Vector Laboratories). Images were taken of each midgut at $16 \mathrm{x}$ magnification with the DsRED filter of the Leica M165 FC stereomicroscope equipped with a DFC3000C digital camera. The resulting images were analyzed by ImageJ [51].

\section{Statistical analysis of adult midguts}

The mean pixel intensity values were normalized to the EGFP control fluorescence values. A linear mixed-effects model analysis on the normalized values was performed using the lme4 package in the R statistical software [61]. GFP was set as the reference for the analysis using the relevel command. The hypothesized formula for the model is given below with the relationship between cell fluorescence and dsRNA gene knockdown accounting for the potential random effects due to the day each experiment was performed and area of a midgut.

$$
\text { Fluorescence } \sim \text { Gene }+(1+\text { Day } \mid \text { Area })+\varepsilon
$$

Finally, all data for each replicate was pooled and graphed using GraphPad Prism v7.02 (San Diego, CA). 


\section{Blood feed of remaining females and 12- and 24-h dissection and ovary measurements}

The remaining females from the pooled dsRNA group and its matching EGFP group were blood fed for $1 \mathrm{~h}$ at $9 \mathrm{am} 3$ days post injection. At 12- and 24-h post blood feeding $~ 30$ females were dissected harvesting the midguts and the ovaries. Post removal of the meal for each midgut, the midguts were pooled in $50 \mu \mathrm{L} 1 \mathrm{x}$ PBS for each group and frozen in liquid $\mathrm{N}_{2}$ before storage at $-80^{\circ} \mathrm{C}$. Each pair of ovaries was photographed at $25 \mathrm{x}$ magnification with the MU300 AmScope microscope digital camera attached to a Leica M60 microscope (AmScope Irvine, CA; Leica, Germany) on a reticle stage micrometer microscope slide (Electron Microscopy Sciences, PA).

\section{Ovary size calculation and statistical analysis}

The resulting ovary images were analyzed by ImageJ [51] to measure the size of each ovary. Ovary size was scaled by using the $100 \mu \mathrm{m}$ ruler present on the slide and normalized to the EGFP control ovary measurements. Finally, all data for each replicate was pooled and a twotailed unpaired t-test performed using GraphPad Prism v7.02 (San Diego, CA).

\section{RT-qPCR validation of RNAi knockdown and RNA-seq}

Quantitative real-time PCR (RT-qPCR) was performed on a CFX69 Touch Real-Time PCR Detection System with SsoAdvanced Universal SYBR Green Supermix (Bio-Rad, $\mathrm{CA}$ ). Primers were designed using the Primer3 server (version 4.1.0) aiming for sequence length of $80-150 \mathrm{bp}$ with DNA hairpin folding accounted for using mfold with the folding temperature set to $60^{\circ} \mathrm{C}$ and $\mathrm{Mg}^{++}$concentration set to $1.5 \mathrm{mM}[62,63]$. Each primer pair was tested with an annealing temperature gradient and pairs with a single peak in their melt curves at 59 or $61.4^{\circ} \mathrm{C}$ were then empirically verified to have percent amplification efficiencies ranging from 90 to $110 \%$. The gene rpS7, AAEL009496, was used as a reference housekeeping gene; the primer sequences, annealing temperature and primer efficiency for it and the other primers used are shown in Supplemental Table 6 (Additional file 2). The program run on the thermocycler was $95^{\circ} \mathrm{C}$ for $30 \mathrm{~s}$, followed by 39 cycles of $15 \mathrm{~s}$ at $95^{\circ} \mathrm{C}$ and $30 \mathrm{~s}$ at 59 or $61.4^{\circ} \mathrm{C}$ annealing temperature finishing with a melt curve of $65-95^{\circ} \mathrm{C}$ measuring every $0.5^{\circ} \mathrm{C}$. For the genes involved in RNAi knockdown confirmation, the RT-qPCR results were normalized to the EGFP knockdown control samples and graphed using GraphPad Prism v7.02 (San Diego, CA). Statistical significance between the control EGFP and each gene knockdown was determined using an unpaired two-tailed $\mathrm{t}$-test $(\alpha<0.05)$. Otherwise, the RT-qPCR $\log 2$ relative quantification values were compared to the $\log 2$ fold change values obtained from the differential expression analysis using GraphPad Prism.

\section{Supplementary information}

Supplementary information accompanies this paper at https://doi.org/10. 1186/s12864-020-06981-5.

Additional file 1 RNA-seq_Supplement_tables. Table S1-S5: All RNA-seq transcriptomic analyses for all conditions examined. This file includes the full spreadsheet for the differential expression and soft cluster analyses of all genes examined. Table S1. Aag2 cells exposed to $10 \mu \mathrm{M}$ Heme or $0 \mu \mathrm{M}$ Heme in Schneider's Drosophila growth media for 72-h. Table S2: Aag2 cells exposed to $20 \mu \mathrm{M}$ Heme for 48-h. Table S3: A20 cells exposed to $10 \mu \mathrm{M}$ Heme or $0 \mu \mathrm{M}$ Heme for $72-\mathrm{h}$. Table S4: Aag2 cells exposed to $10 \mu \mathrm{M}$ Heme or $0 \mu \mathrm{M}$ Heme in Leibovitz's L-15 growth media for 72-h. Table S5: Ae aegypti midguts exposed to $10 \mu \mathrm{M}$ Heme or $0 \mu \mathrm{M}$ Heme in Schneider's Drosophila growth media for 35-h.

Additional file 2. Table S6. Primers utilized for RT-qPCR and dsRNA production. This file includes the primer sequences for all primers utilized in the Real Time quantitative-PCR and dsRNA production described in this paper.

Additional file 3. Supplemental_Text. This file includes the supplemental text describing the details of the additional cultured cell experiments performed in Aag2 cells and A20 cells.

Additional file 4 Fig. S1. Treatment conditions of A20 and Aag2 mosquito cells prior to RNAseq analysis. Schematic representation of the various treatments used to prepare samples for RNAseq. Cell type (Aag2/ A20), incubation time ( $48 \mathrm{~h}, 72 \mathrm{~h}$ ), growth media type (L-15, Schneider's Drosophila), and heme supplement $(0 \mu \mathrm{M}, 10 \mu \mathrm{M}, 20 \mu \mathrm{M})$, with (Normal media, indicated by $50 \mathrm{~mL}$ conical tube) or without (indicated by mini centrifuge tube) FBS present in the media. Schematic was generated using Biorender through a license from Texas A\&M University. Fig. S2. Multidimensional Scaling Plot of RNAseq data derived from Aag2 cultured cells grown in Schneider's Drosophila medium. Multidimensional scaling plot displaying transcriptomic changes in Aag2 cells grown in Schneider's Drosophila medium exposed to heme overload or heme deficiency conditions. The cells grown in normal growth media are circled in blue (FBS), the cells exposed to heme overload are circled in green (10 $\mu \mathrm{M}$ Heme) and the cells exposed to heme deficiency are circled in orange (0 $\mu \mathrm{M}$ Heme). Fig. S3. RNAseq-based transcriptomic analyses after 48-h heme treatment in Aag2 cells. (A) Multidimensional scaling plot. The FBS treated group is circled in blue and the FBS $+20 \mu \mathrm{M}$ heme group is circled in green. (B) Log2 fold change (logFC) vs Log10 counts per million (logCPM) plots of expressed genes; genes with an adjusted $p$-value corrected for multiple testing (False discovery rate: FDR) of $<0.0001$ are shown in red. (C) Volcano plot of genes expressed in analysis. (D) 6 distinct gene expression profile clusters were identified through soft clustering. Only those genes with membership scores $>50 \%$ are shown in each cluster. Red lines show high membership in a cluster while blue indicates low membership. Heme import-like clusters are highlighted in red and export-like clusters in blue. The different heme treatment groups are given on the X-axis of each cluster; $n$, the number of genes present in a cluster. Fig. S4. Multidimensional Scaling Plot of RNAseq data derived from A20 cells grown in normal, heme-deficient or heme overload media. Cells grown in normal growth media are circled in blue (FBS), the cells exposed to heme overload are circled in green (10 $\mathrm{MM}$ Heme) and the cells exposed to heme deficiency are circled in orange (0 $\mathrm{\mu M}$ Heme). Fig. S5. Multidimensional Scaling Plot of RNAseq data derived from Aag2 cultured cells grown in L-15 media. Multidimensional scaling plot displaying transcriptomic changes in Aag2 cells grown in L15 media exposed to heme overload or heme deficiency conditions. The cells grown in normal growth media are circled in blue (FBS), the cells exposed to heme overload are circled in green (10 $\mu \mathrm{M}$ Heme) and the cells exposed to heme deficiency are circled in orange (0 $\mu \mathrm{M}$ Heme). Fig. S6. RNAseq-based transcriptomic analysis after 72-h heme treatment in A20 cells. A20 cells grown with FBS, $0 \mu \mathrm{M}$ heme and $10 \mu \mathrm{M}$ heme $(\mathbf{A}-\mathbf{C})$ Log2 fold change (LogFC) vs Log10 counts per million (LogCPM) graph of genes expressed in analysis for each comparison. Genes with an adjusted $p$-value corrected for multiple testing (False discovery rate: FDR) of < 0.0001 are shown in red. (D-F) Volcano plot of genes expressed in analysis. (A\&D) FBS vs $10 \mu \mathrm{M}$ heme $(\mathbf{B} \& \mathbf{E})$ FBS vs $0 \mu \mathrm{M}$ heme $(\mathbf{C} \& \mathbf{F}) 0 \mu \mathrm{M}$ 
heme vs $10 \mu \mathrm{M}$ heme. (G) 15 gene expression profile clusters were identified through soft clustering. All genes retained in a cluster scored $>50 \%$ membership to that cluster. Red lines indicate high membership values in the cluster, blue indicates low membership. The different heme treatment groups are given on the X-axis of each cluster. Heme import-like clusters are highlighted in red and export-like clusters are highlighted in blue; n, the number of genes present in a cluster. Fig. S7. RNAseq-based transcriptome analysis after 72-h heme treatment of Aag2 cells grown in L-15 media. Aag2 cells grown with FBS, with $0 \mu \mathrm{M}$ heme or with $10 \mu \mathrm{M}$ heme (A-C) Log2 fold change (LogFC) vs Log10 counts per million (LogCPM) graph of genes expressed for each comparison. Genes with an adjusted $p$-value corrected for multiple testing of $<0.0001$ are shown in red. (D-F) Volcano plot of genes expressed in analysis. (A\&D) FBS vs $0 \mu \mathrm{M}$ heme (B\&E) FBS vs $10 \mu \mathrm{M}$ heme (C\&F) $0 \mu \mathrm{M}$ heme vs $10 \mu \mathrm{M}$ heme. (G) 15 gene expression profile clusters were identified through soft clustering. Only genes with membership scores of $>50 \%$ are shown in each cluster. Red lines indicate high membership values in the cluster, blue indicates low membership. Heme import-like clusters are highlighted in red and export-like clusters are highlighted in blue. The different heme treatment groups are given on the $\mathrm{X}$-axis of each cluster; $\mathrm{n}$, the number of genes present in a cluster. Fig. S8. TM containing genes shared between the differential expression analysis and the cluster analysis of Aag2 cells treated with heme for $72 \mathrm{~h}$ in Schneider's Drosophila media. Transmembrane domain containing genes found significantly expressed in DE analysis were compared to those identified in the cluster analysis. (A) Downregulated genes in the absence of heme vs Upregulated genes in the presence of heme vs those in import-like clusters. (B) Downregulated genes in the absence of heme vs Upregulated genes in the presence of heme vs those found in export-like clusters. Fig. S9. TM containing genes shared between the differential expression analysis and the cluster analysis of Aag 2 cells treated with heme for $48 \mathrm{~h}$. Transmembrane domain containing genes found significantly expressed in DE analysis were compared to those identified in the cluster analysis. (A) Upregulated genes in the presence of heme vs those in import-like clusters. (B) Downregulated genes in the presence of heme vs those found in export-like clusters.

Fig. S10: TM containing genes shared between the differential expression analysis and the cluster analysis of A20 cells treated with heme for $72 \mathrm{~h}$. Transmembrane domain containing genes found significantly expressed in DE analysis were compared to those identified in the cluster analysis. (A) Downregulated genes in the absence of heme vs Upregulated genes in the presence of heme vs those in import-like clusters. (B) Downregulated genes in the absence of heme vs Upregulated genes in the presence of heme vs those found in export-like clusters. Fig. S11. TM containing genes shared between the differential expression analysis and the cluster analysis of Aag2 cells treated with heme for $72 \mathrm{~h}$ in Leibovitz's $\mathrm{L}-15$ media. Transmembrane domain containing genes found significantly expressed in DE analysis were compared to those identified in the cluster analysis. (A) Downregulated genes in the absence of heme vs Upregulated genes in the presence of heme vs those in import-like clusters. (B) Downregulated genes in the absence of heme vs Upregulated genes in the presence of heme vs those found in export-like clusters. Fig. S12. Potential Heme Importers and Exporters found in independent RNA-seq experiments after treatment with Heme. Candidate genes were chosen in each heme exposed cultured cell dataset based on expression pattern and having at least one transmembrane domain prediction. Expression patterns expected for potential transcriptionally regulated exporters $(\mathbf{A})$ or importers (B). Fig. S13: Heme treatment reduces ZnMP uptake in $A e^{-}$ des aegypti female midguts at multiple heme concentrations. Ae. aegypti female midguts were incubated in varying concentrations of heme ranging from $0 \mu \mathrm{M}$ to $10 \mu \mathrm{M}$. Photos for each heme concentration taken before (A) or after (B) ZnMP incubation. Raw fluorescence intensity (C) or background corrected (D) measurements of each midgut. Red-filled points correspond to the matching photo given in $(\mathbf{A})$ or $(\mathbf{B}) . W L=$ White Light. Fig. S14. Multidimensional scaling plot of RNAseq data derived from heme treated midguts. Multidimensional scaling plots displaying transcriptomic changes in dissected Ae. aegypti midguts exposed to heme overload or heme deficiency conditions. The midgut replicates exposed to heme overload are circled in green ( $10 \mu \mathrm{M}$ Heme) and the midgut replicates exposed to heme deficiency are circled in orange ( $0 \mu \mathrm{M}$ Heme). (A) MDS plot containing all 4 replicates of both heme treatments. 2 samples do not cluster with their other replicates, $0 \mu \mathrm{M}$ replicate 1 and $10 \mu \mathrm{M}$ replicate 2 , circled in red. (B) MDS plot containing 3 replicates per heme treatment as the 2 samples that failed to cluster with their groups were removed.

Additional file 5 Supplemental code file. This file contains an example set of Linux commands used to perform random sampling of Ae. aegypti genome for genes encoding proteins with transmembrane domain predictions

\section{Abbreviations}

AelMUCl: Ae. aegypti intestinal mucin 1; BV: Biliverdin; ZnMP: Zinc Mesoporphyrin; FBS: Fetal bovine serum; DEG: Differentially expressed genes; TM: Transmembrane; ROS: Reactive oxygen species; logFC: Log2 fold change; logCPM: Log10 counts per million; RQ: Relative quantification; RT-qPCR: Realtime quantitative polymerase chain reaction; dsRNA: Double-stranded RNA

\section{Acknowledgements}

We thank the members of the Adelman lab for technical assistance, specifically Michelle Anderson for her work on the 48-h heme-exposed Aag2 cell experiment and Loraine O. Springer for her work on the RNAi screen of adult females. Portions of this research were conducted with high performance research computing resources provided by Texas A\&M University (https://hprc.tamu.edu).

\section{Authors' contributions}

HE and ZA were responsible for study design. HE performed experiments and analyzed the data. HE and ZA drafted the manuscript. HE and ZA approved the final version.

\section{Funding}

This study was supported by the national Institute of Allergies and Infectious Diseases of the National Institutes of Health under the award number Al115138 and by the Texas A\&M AgriLife Research Insect-Vectored Disease Grant Program.

\section{Availability of data and materials}

The datasets generated and/or analyzed during the current study are available in the GEO repository, under the accession numbers: GSE141651 (Cultured cell datasets) and GSE140752 (Midgut). A20 and Aag2 cell lines, as well as LVP strain Ae. aegypti mosquitoes are available upon request. Ae. aegypti genome data is available at www.vectorbase.org.

\section{Ethics approval and consent to participate}

Not applicable.

\section{Consent for publication}

Not applicable.

\section{Competing interests}

The authors declare that they have no competing interests.

\section{Author details}

${ }^{1}$ Genetics Graduate Program, Texas A\&M University, College Station, TX 77843, USA. ${ }^{2}$ Department of Entomology, 329A Heep Center, Texas A\&M University, 370 Olsen Blvd, College Station, TX 77843, USA.

Received: 6 April 2020 Accepted: 11 August 2020

Published online: 31 August 2020

\section{References}

1. Gatherer D, Kohl A. Zika virus: a previously slow pandemic spreads rapidly through the Americas. J Gen Virol. 2016;97(2):269-73.

2. Mukherjee D, Das S, Begum F, Mal S, Ray U. The mosquito immune system and the life of dengue virus: what we know and do not know. Pathogens. 2019;8(2). https://doi.org/10.3390/pathogens8020077. 
3. Lim EXY, Lee WS, Madzokere ET, Herrero L. Mosquitoes as suitable vectors for Alphaviruses. Viruses. 2018;10(2):84.

4. Coffey LL, Failloux AB, Weaver SC. Chikungunya virus-vector interactions. Viruses. 2014;6(11):4628-63.

5. Alonso-Palomares LA, Moreno-Garcia M, Lanz-Mendoza H, Salazar MI. Molecular basis for Arbovirus transmission by Aedes aegypti mosquitoes. Intervirology. 2018;61(6):255-64

6. Barillas-Mury C, Wells MA. Cloning and sequencing of the blood mealinduced late trypsin gene from the mosquito Aedes aegypti and characterization of the upstream regulatory region. Insect Mol Biol. 1993; 2(1):7-12.

7. Jiang Q, Hall M, Noriega FG, Wells M. cDNA cloning and pattern of expression of an adult, female-specific chymotrypsin from Aedes aegypti midgut. Insect Biochem Mol Biol. 1997;27(4):283-9.

8. Edwards MJ, Moskalyk LA, Donelly-Doman M, Vlaskova M, Noriega FG, Walker VK, et al. Characterization of a carboxypeptidase a gene from the mosquito, Aedes aegypti. Insect Mol Biol. 2000;9(1):33-8.

9. Brackney DE, Isoe J, Black WC IV, Zamora J, Foy BD, Miesfeld RL, et al. Expression profiling and comparative analyses of seven midgut serine proteases from the yellow fever mosquito, Aedes aegypti. I Insect Physiol. 2010;56(7):736-44

10. Marquardt WC, Kondratieff BC. Biology of disease vectors. 2nd ed. Burlington, MA: Elsevier Academic Press; 2005.

11. Zhou G, Kohlhepp P, Geiser D, MdC F, Vazquez-Moreno L, Winzerling JJ. Fate of blood meal iron in mosquitoes. J Insect Physiol. 2007;53(11):1169-78.

12. Martin D, Wang SF, Raikhel AS. The vitellogenin gene of the mosquito Aedes aegypti is a direct target of ecdysteroid receptor. Mol Cell Endocrinol. 2001; 173(1-2):75-86.

13. Segraves WA. Steroid receptors and orphan receptors in Drosophila development. Semin Cell Dev Biol. 1994:5(2):105-13.

14. Thummel CS. Flies on steroids--Drosophila metamorphosis and the mechanisms of steroid hormone action. Trends Genet. 1996;12(8):306-10.

15. Kokoza VA, Martin D, Mienaltowski MJ, Ahmed A, Morton CM, Raikhel AS. Transcriptional regulation of the mosquito vitellogenin gene via a blood meal-triggered cascade. Gene. 2001;274(1-2):47-65.

16. Cruz J, Mane-Padros D, Zou Z, Raikhel AS. Distinct roles of isoforms of the heme-liganded nuclear receptor $\mathrm{E75}$, an insect ortholog of the vertebrate rev-erb, in mosquito reproduction. Mol Cell Endocrinol. 2012;349(2):262-71.

17. Tellam RL, Wijfels G, Willadsen P. Peritrophic matrix proteins. Insect Biochem Mol Biol. 1999;29(2):87-101.

18. Pascoa V, Oliveira PL, Dansa-Petretski ML, Silva JR, Alvarenga PH, JacobsLorena $\mathrm{M}$, et al. Aedes aegypti peritrophic matrix and its interaction with heme during blood digestion. Insect Biochem Mol Biol. 2002;32(5):517-23.

19. Shao L, Devenport M, Jacobs-Lorena M. The peritrophic matrix of hematophagous insects. Arch Insect Biochem Physiol. 2001;47(2):119-25.

20. Devenport M, Alvarenga PH, Shao L, Fujioka H, Bianconi ML, Oliveira PL, et al. Identification of the Aedes aegypti Peritrophic matrix protein AelMUC as a Heme-binding proteint. Biochemistry. 2006;45(31):9540-9.

21. Rayms-Keller A, McGaw M, Oray C, Carlson JO, Beaty BJ. Molecular cloning and characterization of a metal responsive Aedes aegypti intestinal mucin cDNA. Insect Mol Biol. 2000;9(4):419-26.

22. Wegiel B, Nemeth Z, Correa-Costa M, Bulmer AC, Otterbein LE. Heme oxygenase-1: a metabolic nike. Antioxid Redox Signal. 2014;20(11):1709-22.

23. Wilks A, Heinzl G. Heme oxygenation and the widening paradigm of heme degradation. Arch Biochem Biophys. 2014;544:87-95.

24. Pereira LO, Oliveira PL, Almeida IC, Paiva-Silva GO. Biglutaminyl-biliverdin IX alpha as a heme degradation product in the dengue fever insect-vector Aedes aegypti. Biochemistry. 2007;46(23):6822-9.

25. Whiten SR, Eggleston H, Adelman ZN. Ironing out the details: exploring the role of Iron and Heme in blood-sucking arthropods. Front Physiol. 2018;8:1134.

26. Rajagopal A, Rao AU, Amigo J, Tian M, Upadhyay SK, Hall C, et al. Haem homeostasis is regulated by the conserved and concerted functions of HRG-1 proteins. Nature. 2008:453(7198):1127-31.

27. Bottino-Rojas V, Talyuli OAC, Jupatanakul N, Sim S, Dimopoulos G, Venancio TM, et al. Heme signaling impacts global gene expression, immunity and dengue virus infectivity in Aedes aegypti. PLoS One. 2015; 10(8):e0135985.

28. Worthington MT, Cohn SM, Miller SK, Luo RQ, Berg CL. Characterization of a human plasma membrane heme transporter in intestinal and hepatocyte cell lines. Am J Physiol Gastrointest Liver Physiol. 2001; 280(6):G1172-G7.
29. Greenbaum NL, Kappas A. Comparative photoactivity of tin and zinc porphyrin inhibitors of heme oxygenase - pronounced photolability of the zinc-compounds. Photochem Photobiol. 1991;54(2):183-92.

30. Bonizzoni M, Dunn WA, Campbell CL, Olson KE, Dimon MT, Marinotti O, et al. RNA-seq analyses of blood-induced changes in gene expression in the mosquito vector species, Aedes aegypti. BMC Genomics. 2011;12(1):82.

31. Tsujimoto H, Anderson MAE, Myles KM, Adelman ZN. Identification of candidate Iron transporters from the ZIP/ZnT gene families in the mosquito Aedes aegypti. Front Physiol. 2018;9:380.

32. Xiao G, Wan Z, Fan Q, Tang X, Zhou B. The metal transporter ZIP13 supplies iron into the secretory pathway in Drosophila melanogaster. eLife. 2014;3.

33. Bottino-Rojas V, Pereira LOR, Silva G, Talyuli OAC, Dunkov BC, Oliveira PL, et al. Non-canonical transcriptional regulation of heme oxygenase in Aedes aegypti. Sci Rep. 2019;9(1):13726.

34. Whiten SR, Ray WK, Helm RF, Adelman ZN. Characterization of the adult Aedes aegypti early midgut peritrophic matrix proteome using LC-MS. PLoS One. 2018;13(3):e0194734.

35. Lara FA, Pohl PC, Gandara AC, Ferreira Jda S, Nascimento-Silva MC, Bechara $\mathrm{GH}$, et al. ATP binding cassette transporter mediates both heme and pesticide detoxification in tick midgut cells. PLoS One. 2015;10(8):e0134779.

36. Gurley JM, Ilkayeva O, Jackson RM, Griesel BA, White P, Matsuzaki S, et al. Enhanced GLUT4-dependent glucose transport relieves nutrient stress in obese mice through changes in lipid and amino acid metabolism. Diabetes. 2016;65(12):3585-97.

37. Liu Y, Nguyen P, Baris TZ, Poirier MC. Molecular analysis of mitochondrial compromise in rodent cardiomyocytes exposed long term to nucleoside reverse transcriptase inhibitors (NRTIs). Cardiovasc Toxicol. 2012;12(2):123-34.

38. Giraldo-Calderon Gl, Emrich SJ, MacCallum RM, Maslen G, Dialynas E, Topalis $P$, et al. VectorBase: an updated bioinformatics resource for invertebrate vectors and other organisms related with human diseases. Nucleic Acids Res. 2015;43(Database issue):D707-13.

39. Stearman R, Yuan DS, Yamaguchi-Iwai Y, Klausner RD, Dancis A. A permease-oxidase complex involved in high-affinity iron uptake in yeast. Science. 1996;271(5255):1552-7.

40. Perner J, Provaznik J, Schrenkova J, Urbanova V, Ribeiro JM, Kopacek P. RNAseq analyses of the midgut from blood- and serum-fed lxodes ricinus ticks. Sci Rep. 2016;6:36695.

41. White C, Yuan X, Schmidt PJ, Bresciani E, Samuel TK, Campagna D, et al. HRG1 is essential for heme transport from the phagolysosome of macrophages during erythrophagocytosis. Cell Metab. 2013;17(2):261-70.

42. Quigley JG, Yang Z, Worthington MT, Phillips JD, Sabo KM, Sabath DE, et al. Identification of a human heme exporter that is essential for erythropoiesis. Cell. 2004;1 18(6):757-66.

43. Duffy SP, Shing J, Saraon P, Berger LC, Eiden MV, Wilde A, et al. The fowler syndrome-associated protein FLVCR2 is an importer of heme. Mol Cell Biol. 2010;30(22):5318-24.

44. Khan AA, Quigley JG. Control of intracellular heme levels: Heme transporters and heme oxygenases. Biochim Biophys Acta, Mol Cell Res. 2011;1813(5): 668-82.

45. Braz GRC, Coelho HSL, Masuda H, Oliveira PL. A missing metabolic pathway in the cattle tick Boophilus microplus. Curr Biol. 1999;9(13):703-6.

46. Rao AU, Carta LK, Lesuisse E, Hamza I. Lack of heme synthesis in a freeliving eukaryote. Proc Natl Acad Sci U S A. 2005;102(12):4270-5.

47. Eide D, Broderius M, Fett J, Guerinot ML. A novel iron-regulated metal transporter from plants identified by functional expression in yeast. Proc Natl Acad Sci U S A. 1996;93(11):5624-8.

48. Wurmthaler LA, Sack M, Gense K, Hartig JS, Gamerdinger M. A tetracyclinedependent ribozyme switch allows conditional induction of gene expression in Caenorhabditis elegans. Nat Commun. 2019;10(1):491.

49. Protchenko O, Shakoury-Elizeh M, Keane P, Storey J, Androphy R, Philpott CC. Role of PUG1 in inducible porphyrin and heme transport in Saccharomyces cerevisiae. Eukaryot Cell. 2008;7(5):859-71.

50. Vreman HJ, Gillman MJ, Stevenson DK. In vitro inhibition of adult rat intestinal heme oxygenase by metalloporphyrins. Pediatr Res. 1989;26(4):362-5.

51. Schindelin J, Arganda-Carreras I, Frise E, Kaynig V, Longair M, Pietzsch T, et al. Fiji: an open-source platform for biological-image analysis. Nat Methods. 2012;9(7):676-82

52. Kim D, Langmead B, Salzberg SL. HISAT: a fast spliced aligner with low memory requirements. Nat Methods. 2015;12(4):357-60.

53. Robinson MD, Smyth GK. Small-sample estimation of negative binomial dispersion, with applications to SAGE data. Biostatistics. 2008;9(2):321-32. 
54. Robinson MD, McCarthy DJ, Smyth GK. edgeR: a bioconductor package for differential expression analysis of digital gene expression data. Bioinformatics. 2010;26(1):139-40.

55. Benjamini Y, Hochberg Y. Controlling the false discovery rate - a practical and powerful approach to multiple testing. J R Stat Soc B. 1995;57(1):289300.

56. Tsirigos KD, Peters C, Shu N, Kall L, Elofsson A. The TOPCONS web server for consensus prediction of membrane protein topology and signal peptides. Nucleic Acids Res. 2015;43(W1):W401-7.

57. Futschik ME, Carlisle B. Noise-robust soft clustering of gene expression timecourse data. J Bioinforma Comput Biol. 2005;3(4):965-88.

58. Kumar L, Futschik ME. Mfuzz: a software package for soft clustering of microarray data. Bioinformation. 2007;2(1):5-7.

59. Oliveros JC. VENNY. An interactive tool for comparing lists with Venn Diagrams. 2007-2015 [2.1:[Available from: http://bioinfogp.cnb.csic.es/tools/ venny/index.html.

60. Gonzalez M, Martin-Ruiz I, Jimenez S, Pirone L, Barrio R, Sutherland JD. Generation of stable Drosophila cell lines using multicistronic vectors. Sci Rep. 2011;1:75.

61. Bates D, Mächler M, Bolker B, Walker S. Fitting linear mixed-effects models using Ime4. J Stat Softw. 2015;67(1):48.

62. Untergasser A, Cutcutache I, Koressaar T, Ye J, Faircloth BC, Remm M, et al. Primer3-new capabilities and interfaces. Nucleic Acids Res. 2012;40(15): e115.

63. Zuker M. Mfold web server for nucleic acid folding and hybridization prediction. Nucleic Acids Res. 2003;31(13):3406-15.

\section{Publisher's Note}

Springer Nature remains neutral with regard to jurisdictional claims in published maps and institutional affiliations.

Ready to submit your research? Choose BMC and benefit from:

- fast, convenient online submission

- thorough peer review by experienced researchers in your field

- rapid publication on acceptance

- support for research data, including large and complex data types

- gold Open Access which fosters wider collaboration and increased citations

- maximum visibility for your research: over $100 \mathrm{M}$ website views per year

At $\mathrm{BMC}$, research is always in progress.

Learn more biomedcentral.com/submissions 